\title{
Optimal parameters selection for SAGD and VAPEX processes
}

\author{
Rizwan A. $\operatorname{Khan}^{1}$ (1) $\cdot$ Abeeb A. Awotunde ${ }^{1}$
}

Received: 10 April 2016/Accepted: 13 November 2016/Published online: 1 December 2016

(c) The Author(s) 2016. This article is published with open access at Springerlink.com

\begin{abstract}
Steam Assisted Gravity Drainage (SAGD) and Solvent Vapor Extraction (VAPEX), both of the techniques have been proved to be successful for the exploitation of heavy oil reservoirs. Field development of heavy oil reservoirs requires careful determination of optimal parameters, well locations and control setting of producers and injectors. In recent years, field development decisions based on sensitivity studies have been shifting toward automated optimization. In this paper, we present the optimal parameter selection for SAGD and VAPEX. We performed the search of optimum parameters; the vertical separation between injector and producer, well controls and well locations. All these parameters have been simultaneously optimized to study and compare the performance of both processes. Also, we present an efficient method to constrain horizontal wells to preset minimum well spacing constraints. This method was then applied to constrain the well spacing between different peers of horizontal wells in the SAGD and VAPEX processes. The particle swarm optimization was used as an optimizer to determine the optimum parameters. The results indicated that the method could successfully determine the optimal parameters while satisfying the spacing constraint imposed by the user. The comparison of the results showed the better performance of SAGD over VAPEX process.
\end{abstract}

Rizwan A. Khan

rizwanahmedkhan@live.com

Abeeb A. Awotunde

awotunde@kfupm.edu.sa

1 King Fahd University of Petroleum and Minerals, Dhahran, Saudi Arabia
Keywords Optimization · Well Placement · Well Controls - Well Spacing · Steam assisted gravity drainage (SAGD) . Vapor extraction (VAPEX)

\section{Introduction}

The global attention gained by unconventional resources is due to its huge number of Original Oil in Place, (OOIP). The heavy oil resources comprise of over six trillion barrels, nearly three or four times of the conventional OOIP in the world. However, high-viscosity and high-density fluid poses numerous operational and economic challenges to produce from the reservoir. Methods for heavy oil extraction include steam injection, cold heavy oil production with sand, steam assisted gravity drainage, vapor extraction, Toe-to-Heel Air Injection (THAI) and open-pit mining for extremely sandy and oil-rich deposits. SAGD technique is a technically effective process for extracting heavy oil from the reservoirs. This process has been successfully executed in different projects to recover heavy oil across the world (Komery et al. 1999; Butler and Jiang 1997; AED 2004; Yee and Stroich 2004; Scott 2002). The VAPEX technique is emerging as an alternate method for heavy oil extraction; however, it has not been tested at field scale (Butler and Mokrys 1998). This process is the modified form of SAGD in which the solvent is injected as an injection fluid instead of steam. In both methods, a pair of horizontal wells (producer/injector) are used to produce heavy oil. The injection fluid is injected into the reservoir by an injector; this fluid then dilutes the oil lowering its viscosity. Gravityassisted flow directs the oil toward the lower well, and the displaced oil is then extracted from a producer positioned underneath the injector; both wells are parallel to each other typically having a well length of 500-1000 m and a 


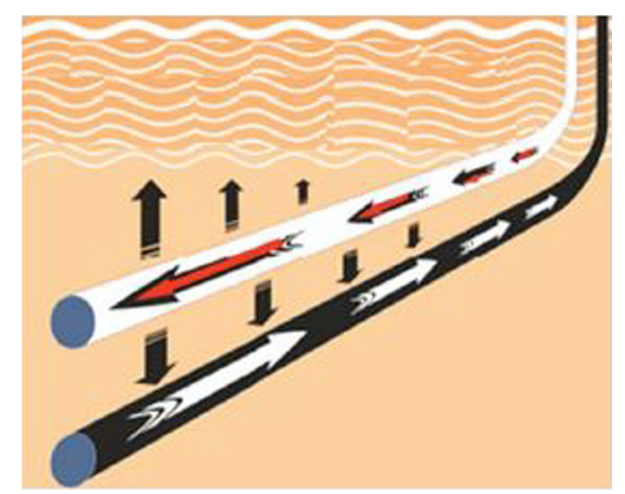

Fig. 1 Well configuration of SAGD and VAPEX (Jorshari and O’Hara 2013)

vertical separation of 5-10 m (Singhal et al. 1998; Komery et al. 1999) as shown in Fig. 1. In the process of SAGD, the injection fluid (steam) transfers heat into the heavy oil to dilute it, while in the VAPEX process, injected solvent vapors dissolve in bitumen at the interface between the solvent and heavy oil and diffuse into the bitumen, thus diluting the oil as shown in schematic in Fig. 2. The key parameters to optimize in both processes include the location of the wells as well as the controls by which to operate the wells. In this study, we considered SAGD and VAPEX processes to determine optimal parameters because both of these processes are similar in operation and have been successfully proven.

Different authors have focused on the optimal parameter selection for SAGD and VAPEX processes (Kisman and Yeung 1995; Butler 1998; Ito and Suzuki 1999; Suggett et al. 2000; Egermann et al. 2001; Edmunds and Chhina 2001; Queipo et al. 2002; Gates and Chakrabarty 2006; Card et al. 2006; Das and Butler 1995; Butler and Jiang 1997, 2000; Butler and Mokrys 1998; Jin 1999; Jiang and Butler 1996; Oduntan et al. 2001; Karmaker and Maini 2003; Yazdani and Maini 2004; Upreti et al. 2007). However, most of them considered sensitivity analysis as a tool for the selection of parameters while very few discussed the importance of automated optimization. In both SAGD and VAPEX processes, researchers have studied the different well configuration to observe the effect on reservoir performance. (Edmunds 1994; Jiang and Butler 1996; Birrell and Putnam 2000; Larter et al. 2008; Parappilly and Zhao 2009; Stalder 2007; Mojarab et al. 2011; Tamer and Gates 2012; Akhondzadeh and Fattahi 2015).

To the best of our knowledge, no work has been reported regarding the optimization of the well locations in SAGD or VAPEX processes. However, significant amount of work has been done in the area of well placement/rate optimization for different field development methods which uses both gradient-based and gradient-free (stochastic) optimization methods. Examples of works in which gradient-based algorithms were used to optimize well locations and/or well rates include Badru and Kabir 2003; Wang et al. 2007; Sarma and Chen 2008; Zandvliet et al. 2008; Forouzanfar et al. 2010. Other works used stochastic algorithms such as GA (Guyaguler et al. 2000; Artus et al. 2006; Ozdogan and Horne 2006; Farshi 2008; Bukhamsin et al. 2010), PSO (Onwunalu and Durlofsky 2010), CMAES (Bouzarkouna et al. 2012; Forouzanfar et al. 2010, 2015; Awotunde and Sibaweihi 2014; DE (Awotunde 2016; Awotunde and Sibaweihi 2014) to solve the well management problem. Stochastic optimization algorithms are considered more robust in solving multidimensional, discontinuous and nonconvex optimization problems. The optimization technique has aided in the enhancement of decision-making process. However, the optimization tools rarely enforce minimum well spacing constraints during the optimization process. In some cases, the optimized results show well locations having higher net present value (NPV) but with the physical limitation of well positioning. Few authors have discussed the importance of well spacing in well placement optimization problem; however, they only focused their study on vertical wells (Emerick et al. 2009; Li et al. 2013; Awotunde and Naranjo 2014; Jesmani et al. 2015).
Fig. 2 Sketch of SAGD and VAPEX configuration (Butler and Mokrys 1991)

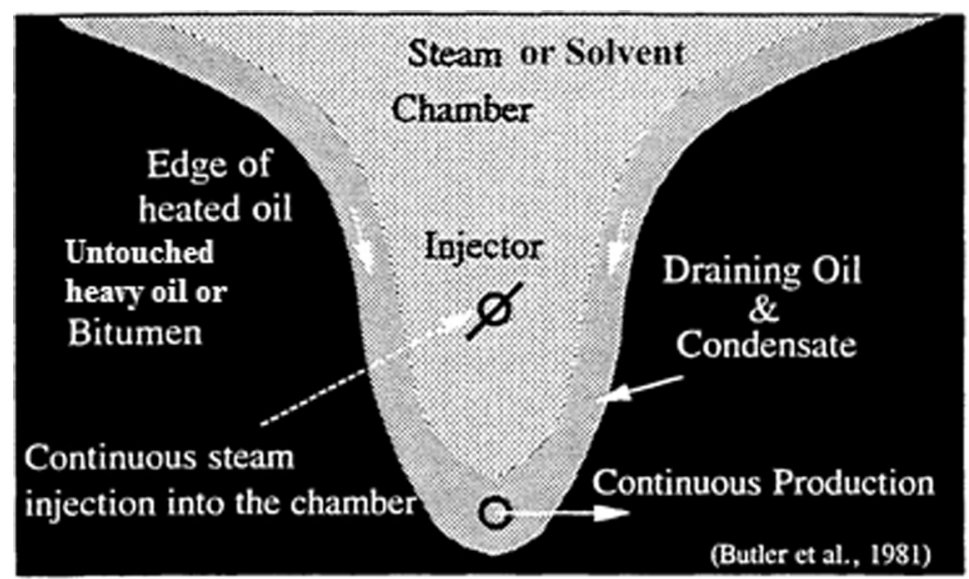




\section{Theoretical background}

\section{Constrained optimization}

A constrained optimization problem (COP) is the technique in which an objective function is to be optimized with respect to specific design variables subjected to some constraints. Mathematically, a constrained optimization problem $(\mathrm{COP})$ can be stated as:

$\min \Phi(\vec{\kappa})$

subject to

$\vec{f}(\vec{\kappa})=0$

$\vec{g}(\vec{\kappa}) \leq 0$

where $\vec{\kappa} \in \mathbb{R}^{M}$ is the vector of design variables and $\Phi(\vec{\kappa})$ : $\mathbb{R}^{X} \rightarrow \mathbb{R}$ is the objective function. The functions $\vec{f}(\vec{\kappa})$ : $\mathbb{R}^{X} \rightarrow \mathbb{R}^{Y}$ and $\vec{g}(\vec{\kappa}): \mathbb{R}^{X} \rightarrow \mathbb{R}^{Z}$ define the equality and inequality constraints, respectively. $X, Y$ and $Z$ are the number of design variables, number of equality constraints and number of inequality constraints, respectively.

\section{Optimization algorithm: particle swarm optimization (PSO)}

Optimization is a process of finding and comparing feasible solutions until no better solution can be found. Global optimization algorithms are based on stochastic processes and are considered to be more effective in finding optimal solutions of nonsmooth, nonconvex or multimodal problems. These optimization algorithms have the ability to move randomly from one region of the problem space to another and hence tend to cover a broader space in their search for optimal solutions. Such algorithms do not require the computation of derivatives and have a higher likelihood of finding the optimum solutions in complex problems. Nevertheless, there is no guarantee that these algorithms will find the overall optimum in a problem space. Also, a major limitation of such algorithms is the computational expense incurred in running them. Particle swarm optimization (PSO) is one of the recently developed optimization algorithm, and it has been used as the global optimizer. In this study, we have only chosen PSO as an optimizer and any other global optimization algorithm can be used instead.

Particle swarm optimization (PSO) is a robust stochastic optimization technique based on the movement of swarms (Eberhart and Kennedy 1995). This technique was motivated by the behavior of organisms as observed in fish schooling and bird flocking in which the fish or birds learn from the successes of one another as they move about in search of food in their respective ecosystem. Thus, the PSO technique searches for the optimum solution using a population of particles, each particle being a vector whose coordinates are the unknown variables of the system. Each particle is thus represented as $\vec{\kappa}_{j} \in \mathbb{R}^{M}$, where $j$ is the particle's index in the swarm and $M$ is the dimension of the problem. In a PSO system, particles in a swarm change their positions by flying around in a multidimensional search space until a relatively unchanging position is encountered or until computational limitations are met. The movements of the particles are both cognitive and social. The cognitive aspects involve each particle learning from its previous successes. On the other side, the social component suggests that individuals ignore their own experience and adjust their behavior according to the successful beliefs of individuals in the neighborhood. These two aspects enable the algorithm to be flexible and well-balanced between global exploration for optimum solutions and local exploitation for desirable solutions. The position attained by each particle is a possible solution to the optimization problem.

In PSO algorithm, the population has $N_{p}$ particles that represent candidate solutions' particles are randomly generated within a predetermined lower and upper bounds and subsequent particle positions are not allowed to all outside these bounds. In the PSO algorithm, each particle, $\vec{\kappa}_{j}$, is a $\mathrm{M}$-dimensional real-valued vector and assigned a zero or random velocity, $\vec{v}_{j}^{k}$, initially. As the particles move around in the problem space, each maintains a memory of its previous best position $\vec{\kappa}_{p, j}$ and the current overall best position ever attained by the entire swarm, $\vec{\kappa}_{g}$. The velocity of the $j$ th particle is updated as

$\vec{v}_{j}^{p+1}=\omega \vec{v}_{j}^{\gamma}+c_{1} r_{1}\left(\vec{\kappa}_{p, j}^{\gamma}-\vec{\kappa}_{j}^{\gamma}\right)+c_{2} r_{2}\left(\vec{\kappa}_{g}-\vec{\kappa}_{j}^{\gamma}\right)$

where $\omega$ is the inertial factor, $c_{1}$ and $c_{2}$ are the cognitive and social parameters, and $r_{1}$ and $r_{2}$ are vectors of uniformly generated random numbers between 0 and 1 . Each particle's position is then updated by Eq. 5 as shown in Fig. 3.

$\vec{\kappa}_{j}^{\gamma+1}=\vec{\kappa}_{j}^{\gamma}+\vec{v}_{j}^{\gamma+1}$.

An objective function by which particles' fitness values are ranked is set. Thus, $\vec{\kappa}_{g}$ is the position with the best objective function value ever visited by any particle in the problem space and $\vec{\kappa}_{p, j}$ is the position with the best objective function value ever witnessed by the $j$ th particle during its movement in the problem space.

Like other algorithms, the PSO performance also depends on the assigned values of the parameters in the algorithm. In this work, the value of $c_{1}$ and $c_{2}$ was set to 1.494 and the weight $(\omega)$ parameter was chosen to be 0.729 ; these parameter values were recommended by Clerc (1999) which 
were shown to perform well for these problems Fernandez Martiınez and Garcia Gonzalo (2011) showed that the choice of PSO parameters $(\omega=0.729, \mathrm{c} 1=\mathrm{c} 2=1.494)$ lies in the region of second-order stability in the PSO parameter space. This implies that the PSO particles have stable trajectories in the optimization space and that the swarm will eventually collapse (Isebor et al. 2014).

\section{Objective function}

Objective functions (fitness, cost, error function) are performance measures that indicate the quality of different alternatives, thereby guiding an optimization algorithm toward finding the optimal solution(s) to a problem. To assess the viability of the different EOR scenarios, NPV becomes a critical yardstick and should be ranked up with the best alternative. The thought supporting the use of NPV as objective functions is to takes more consideration of the economics of the project rather than representing a single value if consider cumulative oil production or else. It recognizes the time value of money and applies the same weighting to all future income. In SAGD/VAPEX project, the capital cost at the project's beginning consists of the exploration cost, the drilling and well completion cost, steam generators capital cost, water treatment capital cost and solvent injection capital cost. The expenditure includes the cost of steam generation, steam injection, produced water treatment, solvent handling and recompression, solvent cost and operating costs including well remediation and human resources.

In an EOR project, the net present value (NPV) is assessed by relationship as

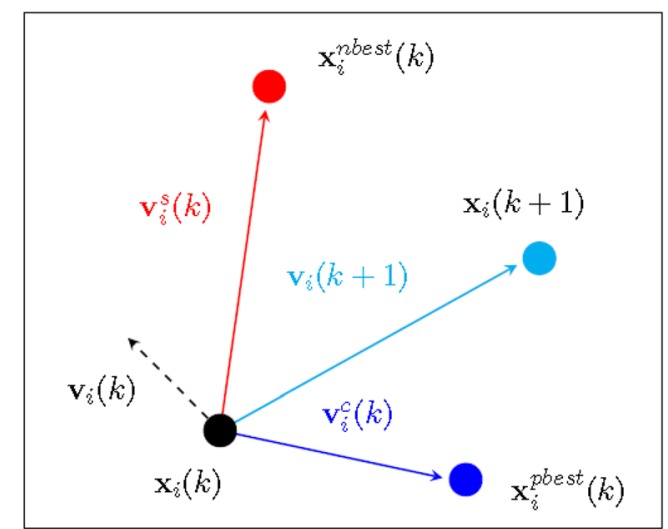

$\begin{array}{llll}\mathbf{x}_{i}(k) & - & \text { current solution } \\ \mathrm{x}_{i}^{\text {pbest }}(k) & - & \text { previous best solution up to } k \\ \mathbf{x}_{i}^{\text {nbest }}(k) & - & \text { neighborhood best solution } \\ \mathrm{x}_{i}(k+1) & - & \text { new solution }\end{array}$

Fig. 3 Representation for PSO particle velocity and particle position update for single particle $x_{i}(k)$ in a two-dimensional search space (Onwunalu and Durlofsky 2010)
$N P V=\sum_{t=1}^{T} \frac{C F_{t}}{(1+r)^{t}}-C_{\text {capex }}$

where $T$ represents total production time in years; $r$ denotes as annual discount rate; $C_{\text {capex }}$ is the capital expenditure, which combines surface facility installation and the total cost to drill and complete all of the wells; and $C F_{t}$ represents the cash flow at time $t$. The capital expenditure $\left(C_{\text {capex }}\right)$ is incurred at time $t=0$ and is calculated as:

$C_{\text {capex }}=\sum_{m=1}^{N_{\text {well }}}\left[C_{m}^{\mathrm{ver}}+L_{m}^{\text {hor }} C^{\text {drill }}\right]+C_{\text {facility }}+C_{\text {exp }}+C_{S G / S O}$

where $N_{\text {well }}$ is the number of wells, $C_{m}^{\mathrm{ver}}$ is the price to drill the vertical section (from surface to the top of the reservoir) $(\$), C^{\text {drill }}$ represents the drilling cost per foot to drill horizontal section of the reservoir (\$/ft.), $L_{m}^{\text {hor }}$ is the length of the horizontal section (ft.), whereas $C_{\text {facility }}$ represents the cost of facility to process oil to the sales point. Cost of exploration well is specified by $C_{\text {exp }}$, where $C_{S G / S O}$ represent cost of steam generation facility in SAGD while in VAPEX it acts a cost of solvent processing facility.

At time $(t)$, the cash flow $C F_{t}$ is given by

$C F_{t}=R_{t}-E_{t}$

where $E_{t}$ and $R_{t}$ stand for operating expenses (\$) and revenue $(\$)$, respectively, which are functions of fluid production volumes at time $(t)$ :

$R_{t}=p_{o} Q_{t}^{o}+p_{g} Q_{t}^{g}$.

In Eq. 9, $p_{o}$ and $p_{g}$ denote the oil price (\$/STB) and gas price $(\$ / \mathrm{SCF}), Q_{t}^{o}$ and $Q_{t}^{g}$ symbolize for the total oil volume (STB) and gas volume (SCF) produced at time $(t)$. In all cases, there is no gas production, so $Q_{t}^{g}=0$. The total operating expense at time $(t), E_{t}$ is calculated for SAGD and VAPEX processes by Eqs. 10 and 11, respectively.

$E_{t, \mathrm{sagd}}=p_{w p} Q_{t}^{w, p}+p_{\text {steaminj }} Q_{t}^{w, i}+p_{o p} Q_{t}^{o}$
$E_{t, \mathrm{vapex}}=p_{w p} Q_{t}^{w, p}+p_{\text {solinj }} Q_{t}^{\text {sol, } i}+p_{o p} Q_{t}^{o}+p_{\text {solrec }} Q_{t}^{\text {sol }}$

where $p_{o p}$ is the operating cost, $p_{w p}$ symbolizes for the costs of water production $(\$ / \mathrm{STB}) ; p_{\text {steaminj }}$ represents steam injection costs $(\$ / \mathrm{STB})$ whereas $p_{\text {solinj }}$ represents cost of solvent injection ( $\$ / \mathrm{STB}) ; Q_{t}^{w, p}, Q_{t}^{w, i}$ and $Q_{t}^{\text {sol }}$ signify the total volumes of water produced (STB) and injected (STB) and the amount of solvent produced, respectively, at time $(t)$. The solvent injection cost and solvent recycling cost are represented by $p_{\text {steaminj }}$ and $p_{\text {solrec }}$, respectively. In all cases, we assume $p_{o}, p_{g}, p_{w p}, p_{w i}$ to be constant with time. The oil price and miscellaneous costs used in calculation of NPV are presented in Table 1. 
Table 1 Cost parameters

\begin{tabular}{lll}
\hline Parameters & Value & Unit \\
\hline Parameters & Value & Unit \\
$C_{\text {facility }}$ & $1.00 \mathrm{E}+06$ & $\mathrm{USD}$ \\
$\mathrm{C}_{\mathrm{SG}}$ & $2.26 \mathrm{E}+06$ & $\mathrm{USD}$ \\
$\mathrm{C}_{\mathrm{SO}}$ & 100000 & $\mathrm{USD}$ \\
$\mathrm{C}_{\mathrm{m}}^{\mathrm{ver}}$ & $6.00 \mathrm{E}+05$ & $\mathrm{USD}$ \\
$\mathrm{C}^{\text {drill }}$ & 600 & $\mathrm{USD} / \mathrm{ft}$. \\
$p_{\mathrm{o}}$ & 65 & $\mathrm{USD} / \mathrm{bbl}$. \\
$p_{\mathrm{g}}$ & 3 & $\mathrm{USD} / \mathrm{MScf}$ \\
$p_{\text {op }}$ & 3 & $\mathrm{USD} / \mathrm{bbl}$. \\
$\mathrm{p}_{\mathrm{wp}}$ & 5 & $\mathrm{USD} / \mathrm{bbl}$. \\
$p_{\text {steaminj }}$ & 8 & $\mathrm{USD} / \mathrm{bbl}$. \\
$p_{\text {solinj }}$ & 2 & $\mathrm{USD} / \mathrm{bbl}$. \\
$p_{\text {solrec }}$ & 0.17 & $\mathrm{USD} / \mathrm{bbl}$. \\
$r$ & 10 & $\%$ \\
\hline
\end{tabular}

\section{Problem formulation}

The decision variables in well placement and rate optimization problem are locations, type, and injection and production rates. In this study, horizontal wells are placed in the $x-y$ plane of the reservoir and the parameterization of their placement in this work is done by using the formulation defined by Farshi (2008). The trajectory of a horizontal well in three-dimensional (3D) space can be mapped as straight line connecting two points in 3D space as shown in Fig. 4. Five design variables are used to define horizontal well, i.e., the three coordinates of heel $\left(x_{1}, y_{1}, z\right)$, total well length $\left(l_{h}\right)$ and the counterclockwise angle $(\theta)$ from the $x$-axis. Other dependent parameters that are necessary to define horizontal well such as coordinates of toe can be calculated during optimization, from the independent variables stated above according to the following equations:

$x_{2}=x_{1}+1_{h} \cos (\theta)$

$y_{2}=y_{1}+l_{h} \sin (\theta)$.

In both SAGD and VAPEX processes, injectors and producers are parallel to each other. Thus, we only

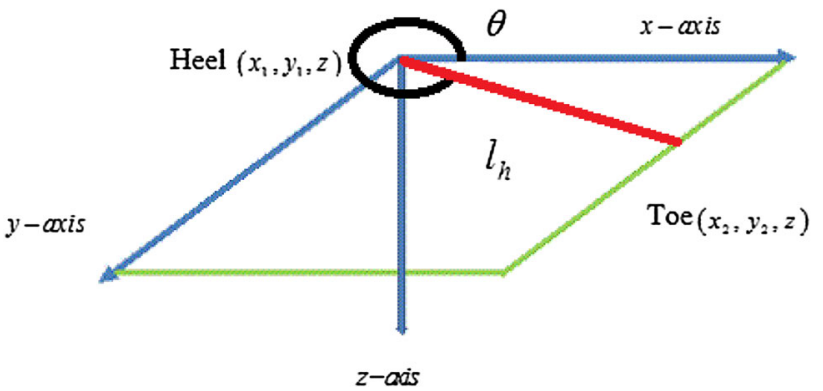

Fig. 4 Representation of horizontal well

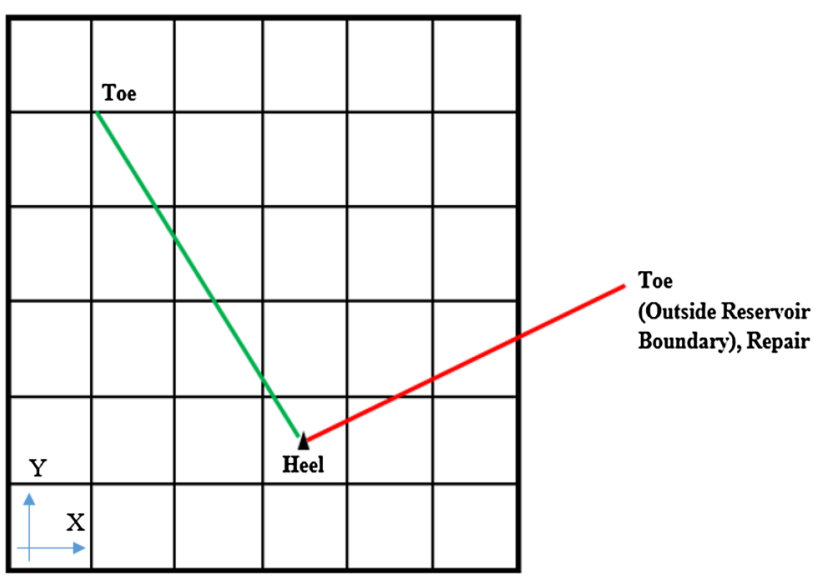

Fig. 5 Repair method illustration for boundary constraint

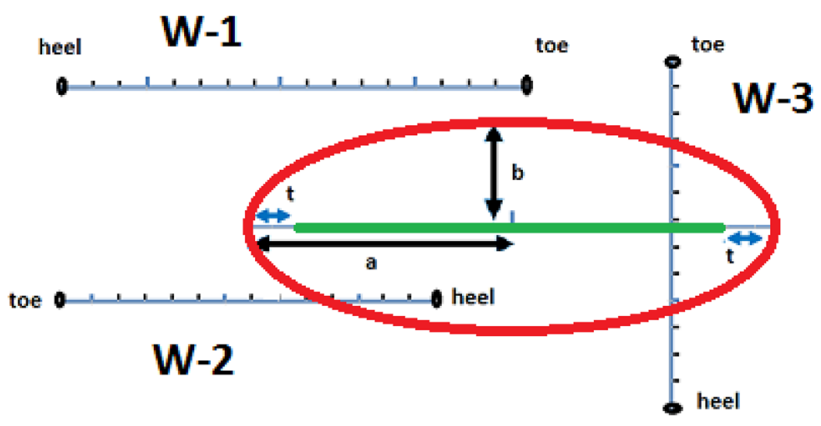

Fig. 6 Horizontal well spacing constraint

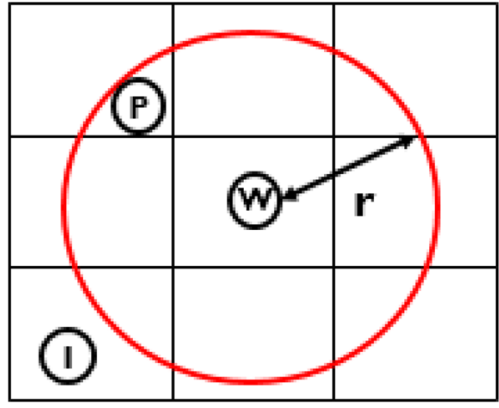

Fig. 7 Vertical well spacing constraint

optimize the location of horizontal injector and the producer is placed at the same location ( $x$ and $y$ ) but in a different layer. In this study, we only consider horizontal well which represent SAGD and VAPEX processes. However, inclined wells can be incorporated with an additional variable in the optimization process.

\section{Well spacing and reservoir boundary constraints}

Intrinsically, global optimization algorithms, including PSO, perform the search for optimum design variables within preset upper and lower bounds on each variable. In addition to this, the optimization routine should be able to 

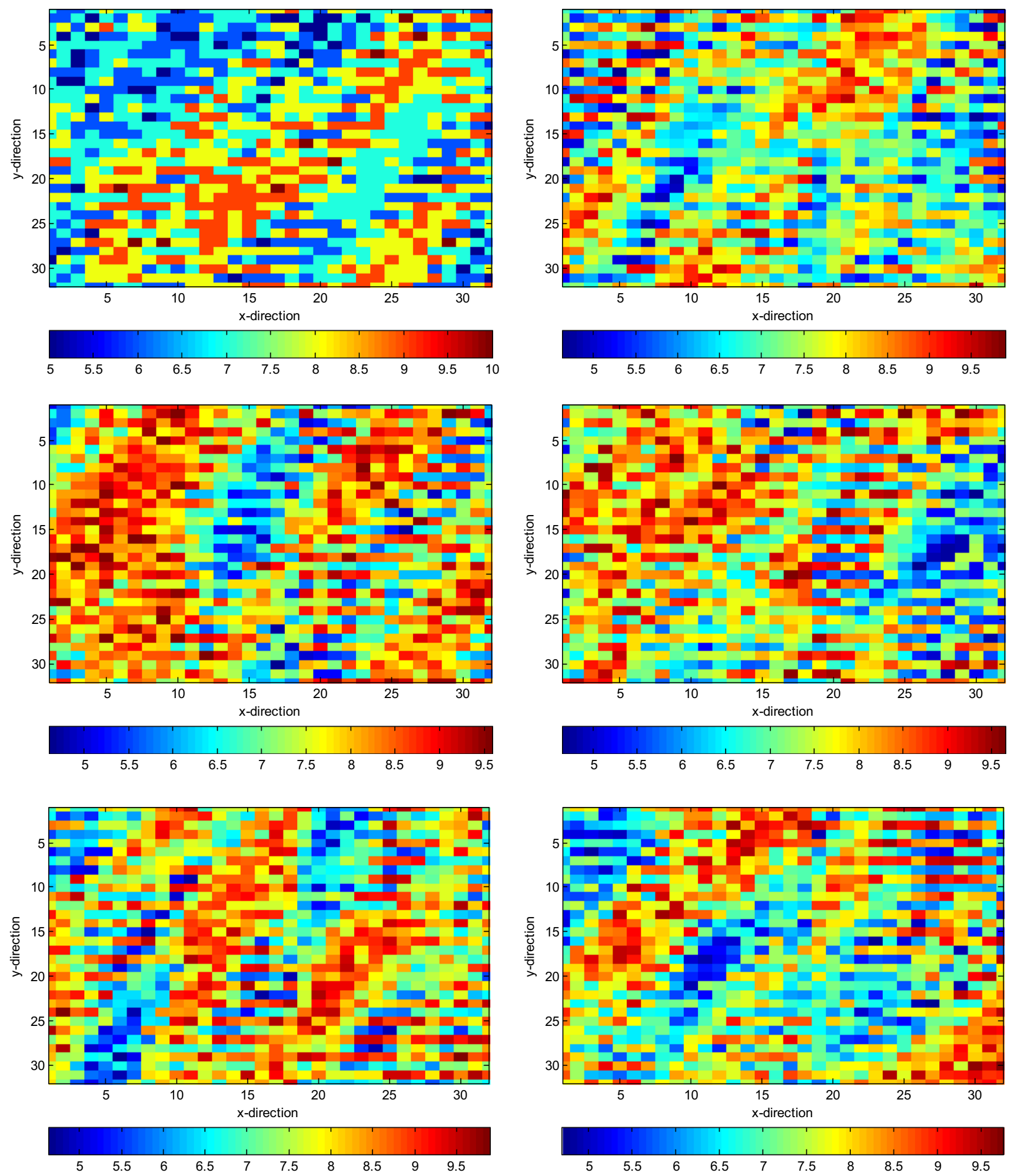

Fig. 8 Log permeability (md) distribution of each layers for both SAGD and VAPEX

handle all structural constraints specified for the horizontal and vertical wells. First, the wells must be placed within the reservoir. In particular, no part of a horizontal well must fall outside the reservoir or cross any external reservoir boundary. This is important because the toe-end of the well may still fall outside the reservoir even if the lower and upper bounds imposed on the optimization variables are met. Thus, there is a need to define additional 

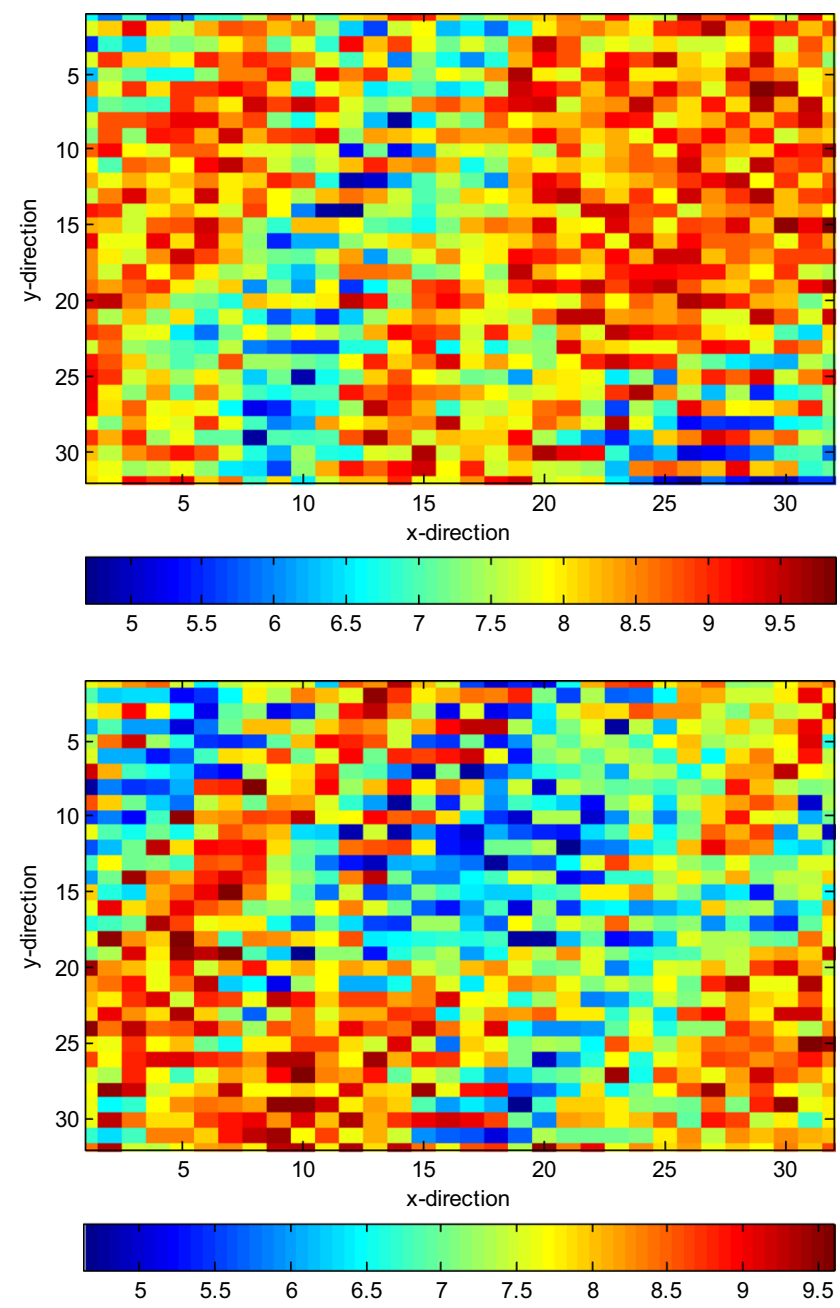

Fig. 8 continued

constraints within which the optimization problem must be solved. This, inevitably, leads to a constrained optimization problem.

The optimization algorithm inherently ensures that a vertical well stays within the reservoir. It also ensures that the heel of the horizontal well falls in the reservoir. However, to ensure that the toe of a horizontal well stays within the reservoir is handled by the repair method (Orvosh and Davis 1993; Engelbrecht 2005) of constraint optimization. In this case, if the toe of the horizontal well falls outside the reservoir, then the angle is regenerated randomly so that the well-toe is rotated into the reservoir and the other well parameters are recomputed to check that all parameters are within the preset bounds. This method is illustrated with a diagram as shown in Fig. 5; the red line shows the horizontal well obtained from the optimizer which were repaired as green line.
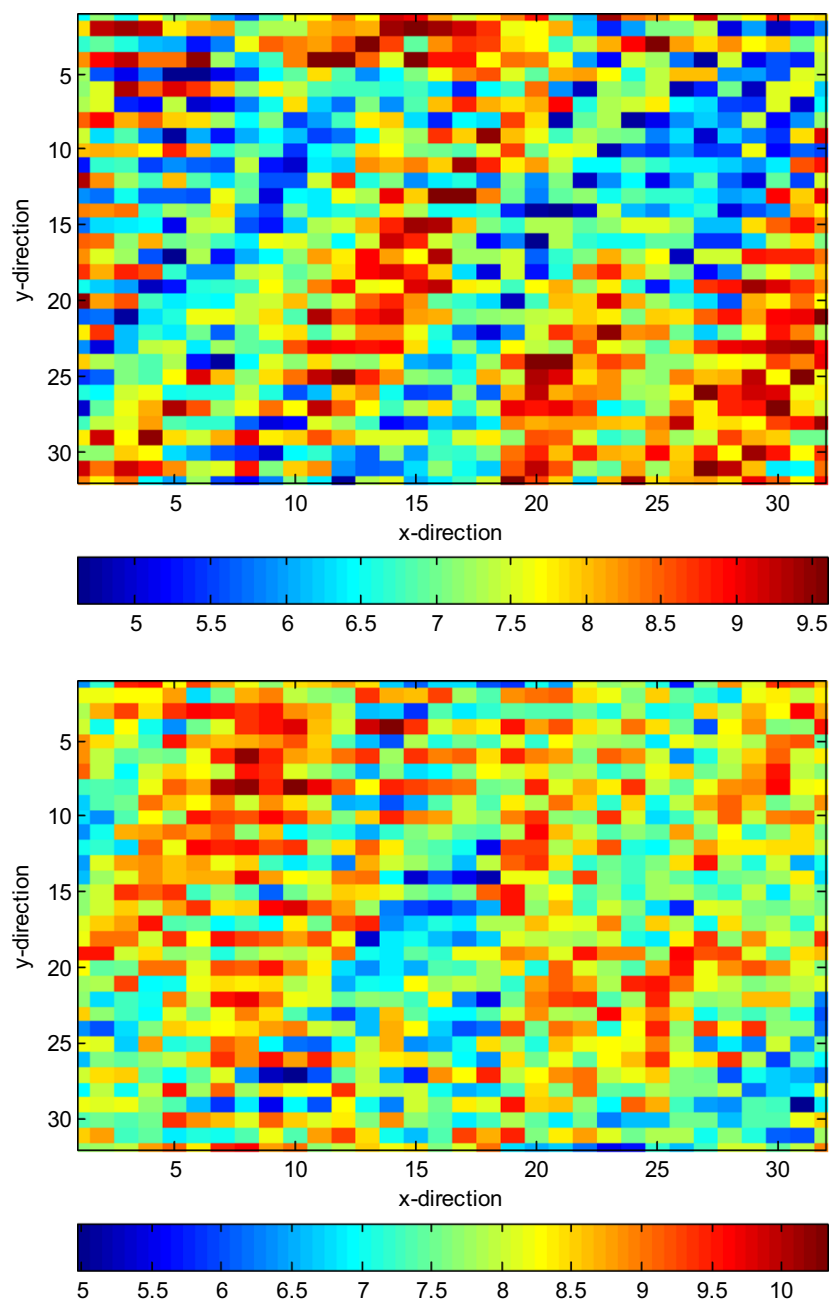

In this study, we suggested a method based on penalty approach (Coello and Carlos 1999; Byrne 2008) to apply well spacing constraint in a horizontal well. To enforce spacing constraint, an ellipse is defined around each horizontal well $i$, estimated by the optimizer. Every point $i$, representing a single vertical well or one of the points on any other horizontal well, is checked against the horizontal well $j$ to ensure the point does not fall within the defined ellipse. Thus, the constraint placed on every horizontal well is

$\frac{\left(x_{i}-x_{j}\right)^{2}}{a^{2}}+\frac{\left(y_{i}-y_{j}\right)^{2}}{b^{2}} \geq 1$

where $\left(x_{j}, y_{j}\right)$ are the coordinates of the center of the horizontal well $j,\left(x_{i}, y_{i}\right)$ are the coordinates of the point $i$ that is checked against well $j, a$ and $b$ are the major and minor axes of the ellipse defined around horizontal well $j$. 
Fig. 9 Porosity (fraction) distribution in z-direction for both models (SAGD and VAPEX)

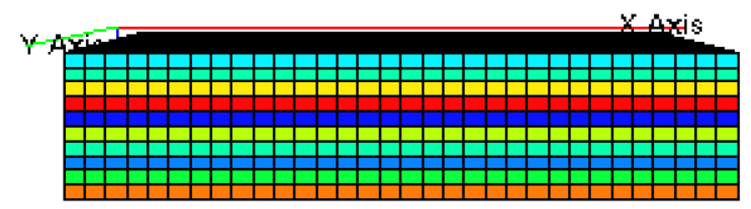

Porosity
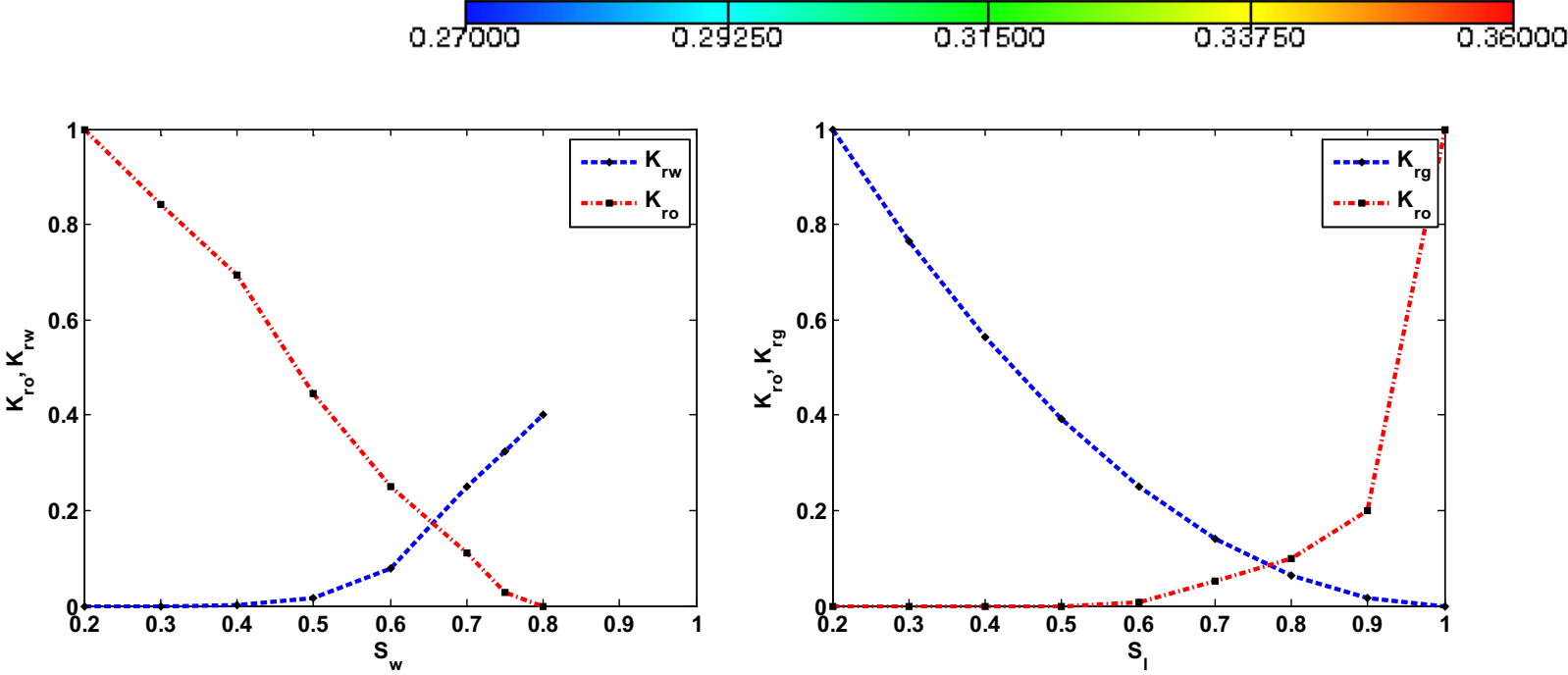

Fig. 10 Relative permeability curves used for both models (SAGD and VAPEX)

The half-length of major and minor axis of ellipse can be calculated with equations as

$a=\frac{\left(l_{j}+2 t\right)}{2}$

$b=2 t$

where $l_{j}$ represents the length of well $j$ and $t$ is the tolerance value. We note that the $x$-axis of the ellipse defined around each horizontal well aligns with the well (regardless of the orientation of the well) so that $a$ is always the major axis and $b$ is always the minor axis. Also, there is no need to consider rotated axes in defining the ellipse as what we needed are simple distances of points from the center of the horizontal well. We have considered a fixed number of points on each horizontal well when checking for violation. The reason for this is that it is possible that several points on a horizontal well will violate the minimum spacing constraint. In fact, it is possible that a horizontal well crosses the minimum circle defined around a vertical well (or the minimum ellipse defined around a horizontal well) at two ends. In this case, we divide every horizontal well into an equal number of points. The points on each horizontal well are equally spaced, and the two ends of the horizontal wells are also considered as two of such points.

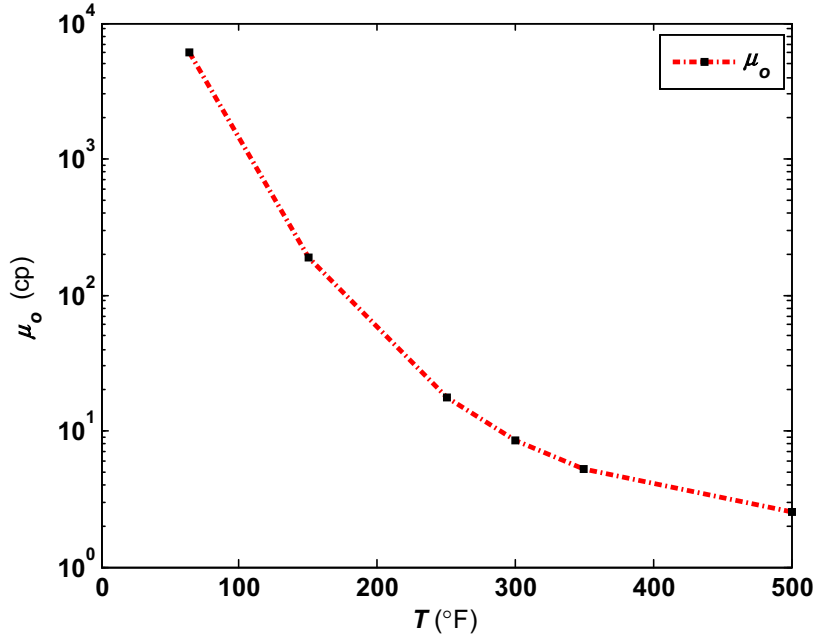

Fig. 11 Viscosity temperature relation for SAGD model

However, the spacing between the points in one horizontal well can be different from the spacing between the points in another horizontal well as shown in Fig. 6. Also, Fig. 6 shows the intensity in the violation of well spacing constraints; it can be seen that well (W-1) satisfies the spacing constraint, while other two well (W-2 and W-3) violate 

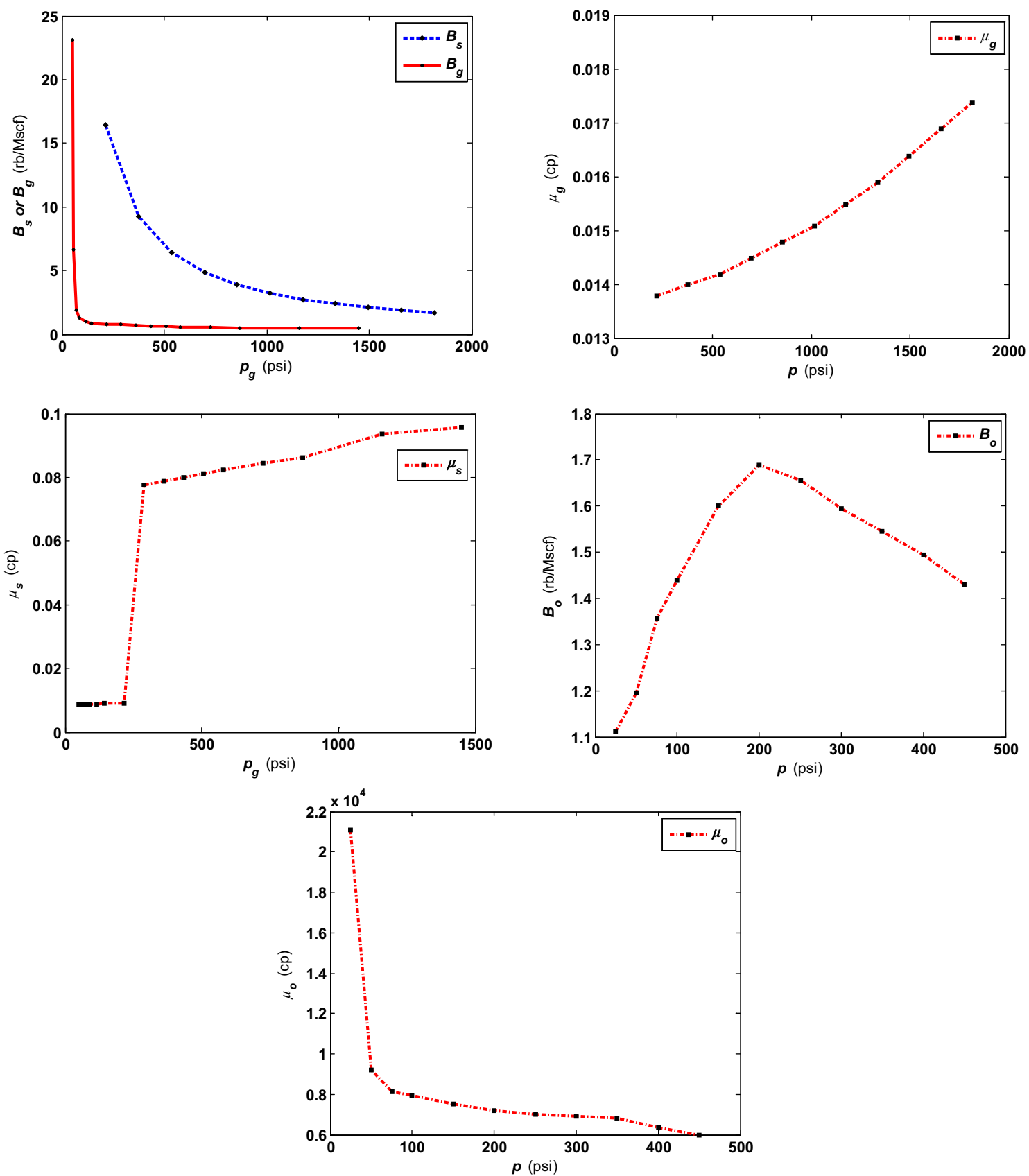

Fig. 12 Fluid properties of gas, oil and solvent used in VAPEX model

spacing constraint with W-3 having large number of violations.

In this problem, the vertical section (heel point) of horizontal well is also tested for spacing constraint. First, a minimum radius $r_{\min }$ is specified for vertical section (heel point) that is estimated by the optimizer. Every point $j$, representing one of the points on any of the estimated horizontal wells is checked against the vertical section (heel point) $i$ to be placed in the reservoir. Any such point that comes within the specified minimum radius is said to violate the minimum spacing of vertical section (heel point) $i$ as represented in Fig. 7 .

Thus, the imposed well constraint on any optimized vertical section $\left(x_{i}, y_{i}\right)$ is

$\left(x_{i}-x_{j}\right)^{2}+\left(y_{i}-y_{j}\right)^{2} \geq r_{\text {min }}^{2}$

where $\left(x_{j}, y_{j}\right)$ is the coordinate of the point $j$ that is checked against well $i$.

Each of these points is then checked against every other well in the reservoir, and where a point violates the 
Table 2 Properties used in SAGD and VAPEX models

\begin{tabular}{ll}
\hline Reservoir properties & \\
\hline Reservoir depth & $396 \mathrm{~m}$ \\
Reservoir thickness & $25 \mathrm{~m}$ \\
Average porosity & $31.30 \%$ \\
Oil viscosity* (RC) & $6000 \mathrm{cp}$ \\
Oil saturation & 0.80 \\
Initial pressure & $450 \mathrm{psi}$ \\
Initial temperature & $64.4{ }^{\circ} \mathrm{F}$ \\
Oil density* (RC) & $20 \mathrm{API}$ \\
Thermal conductivity & $33 \mathrm{Btu} / \mathrm{ft} / \mathrm{day} /{ }^{\circ} \mathrm{F}$ \\
Rock heat capacity & $41 \mathrm{Btu} / \mathrm{ft}^{3} /{ }^{\circ} \mathrm{F}$ \\
Overburden thermal conductivity & $30 \mathrm{Btu} / \mathrm{ft} / \mathrm{day} /{ }^{\circ} \mathrm{F}$ \\
Overburden volumetric heat capacity & $38 \mathrm{Btu} / \mathrm{ft}^{3} /{ }^{\circ} \mathrm{F}$ \\
\hline
\end{tabular}

minimum spacing constraint defined in Eq. 14 or 17, a violation value (a small positive value preset by the user) is assigned to the point. Every violation gets the same value.
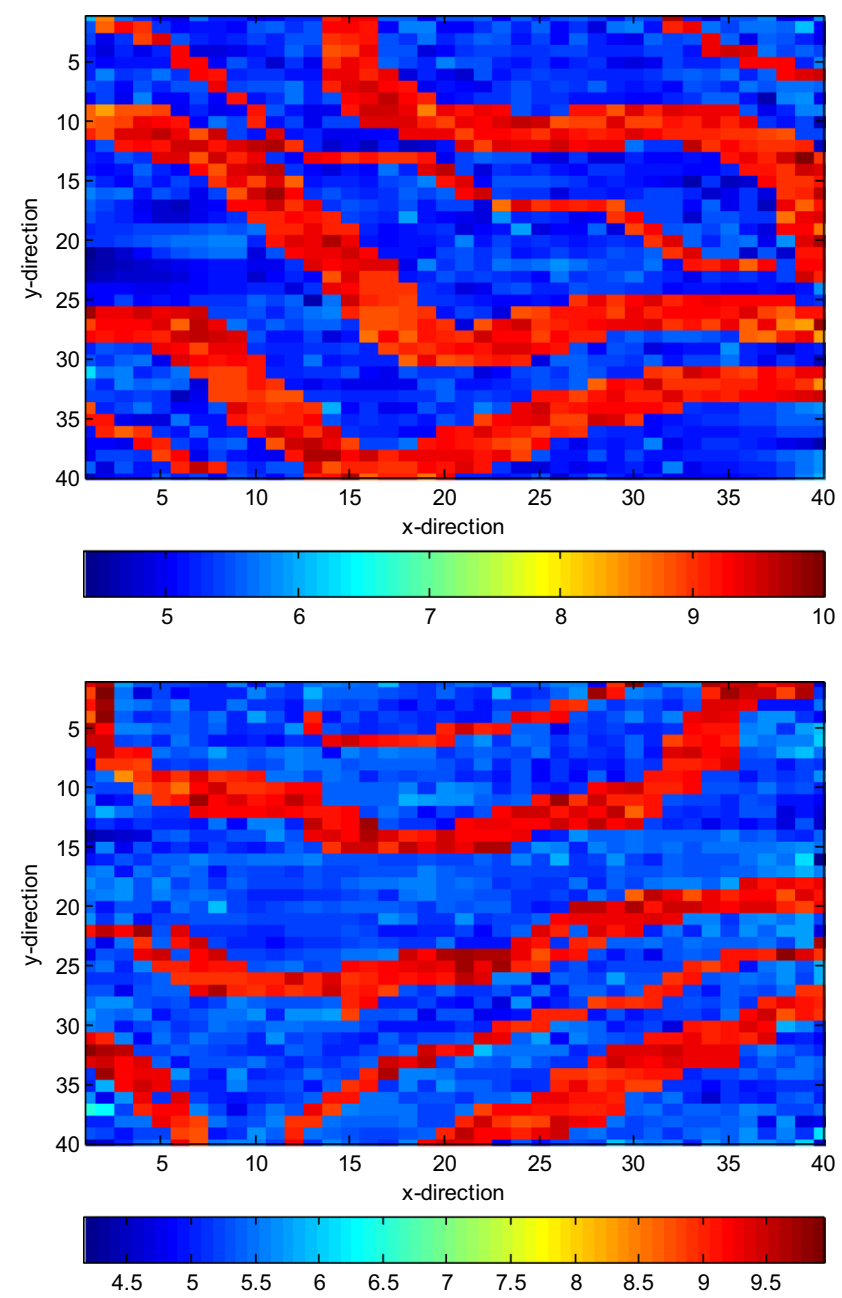

The total sum of violation recorded by a candidate solution is then applied as a penalty to the objective function $(-N P V)$. Thus, if a candidate solution incurs several penalties, the overall objective function $(-N P V+$ penalty) for that candidate may be poor even if its primary objective function $(-N P V)$ is very good. Thus, the search is gradually guided toward the acceptable region of search space.

\section{Implementation}

In this study, we tested the effectiveness of the solution on a heterogeneous reservoir. The algorithm was run over 2000 function evaluations. Each particle in the population has one NPV value and corresponding penalty values. In all cases, objective function is composed of the sum of NPV and the penalty values (after both have been properly scaled) are used. At the first iteration, the median and mean value is selected as the scaling factor for NPV and violations, respectively. The
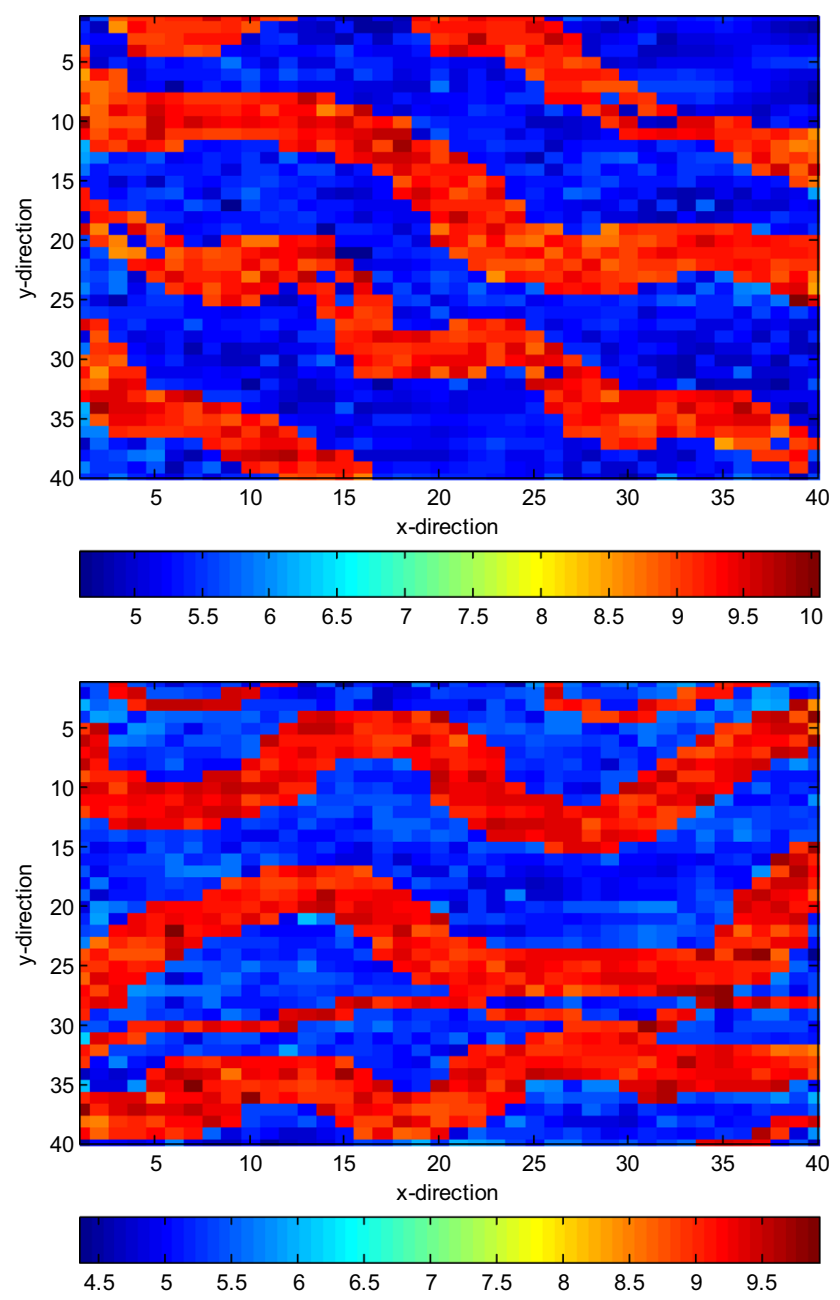

Fig. 13 Channel reservoir permeability (md) distribution, Example 2 


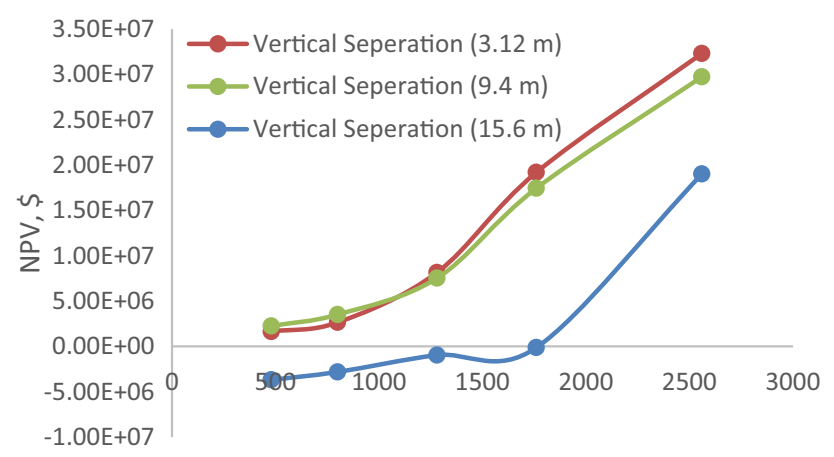

Well Length, $\mathrm{ft}$

Fig. 14 Effect of vertical separation, SAGD

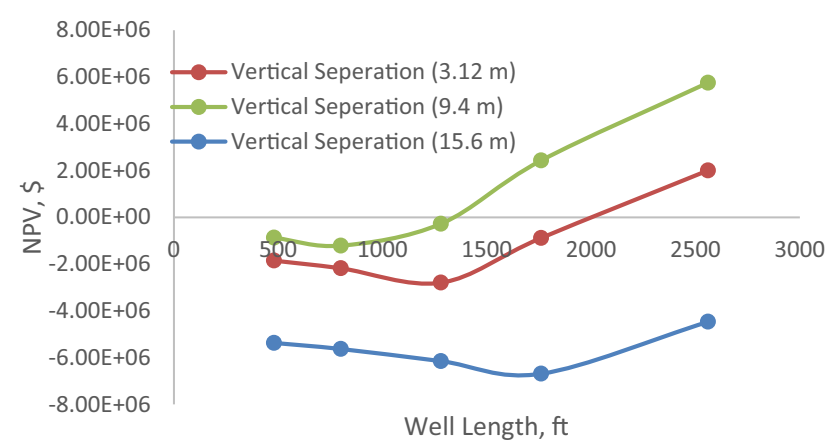

Fig. 15 Effect of vertical separation, VAPEX

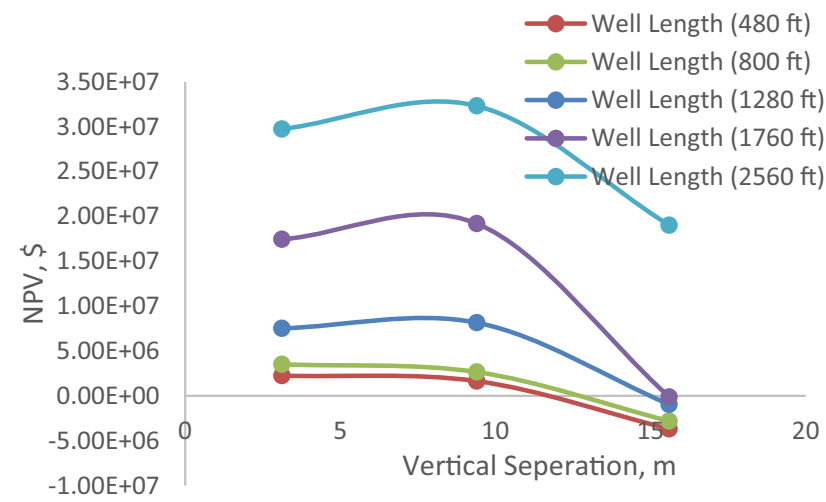

Fig. 16 Effect of well length, SAGD

price and cost functions were assumed to be constant throughout the operating duration.

In this work, the maximum possible length of any well is specified as $2500 \mathrm{ft}$. A minimum well spacing of 10 acres was enforced around each vertical well. In enforcing a minimum well spacing around any well that is estimated by the optimizer to be a horizontal well, an ellipse surrounding the well is formed. The area corresponding to this ellipse is dependent on the estimated length of the horizontal well. Because the horizontal well length varies from one well to the other, the areas of the ellipse for different wells also

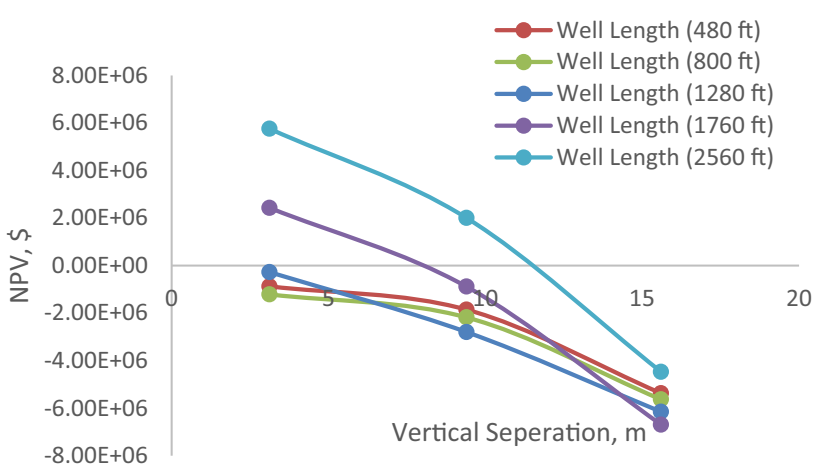

Fig. 17 Effect of well length, VAPEX

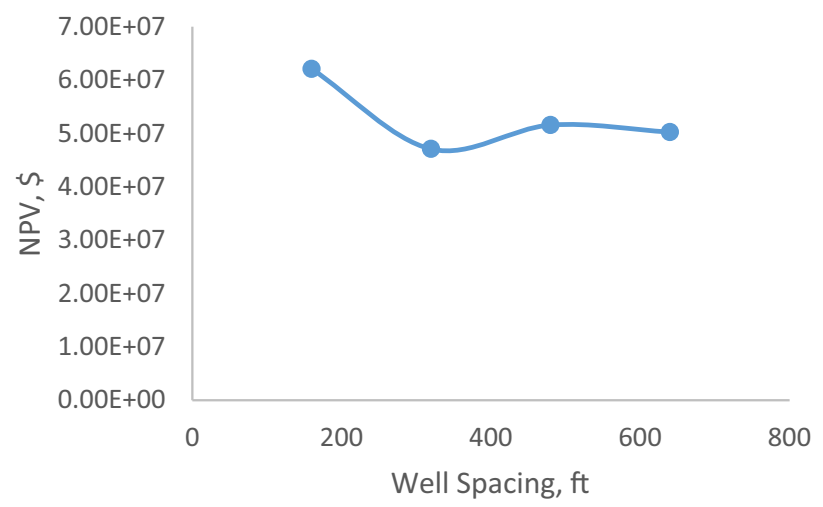

Fig. 18 Effect of well spacing, SAGD

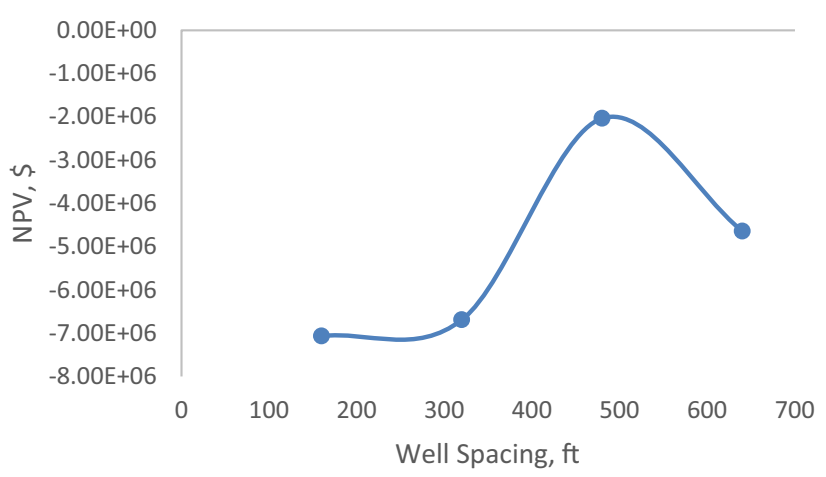

Fig. 19 Effect of well spacing, VAPEX

vary. A tolerance of $200 \mathrm{ft}$. was added to the half-length of each horizontal well to obtain the half-length of the major axis of the ellipse that forms the constraining area around the corresponding horizontal well. The half-length of the minor axis of this ellipse was set as $400 \mathrm{ft}$.

\section{Example 1: reservoir with distributed permeability field}

This example demonstrates the synthetic reservoir with a randomly distributed permeability field used for

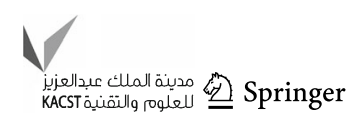




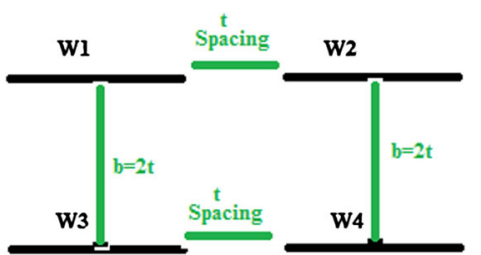

Fig. 20 Schematic for well spacing effect

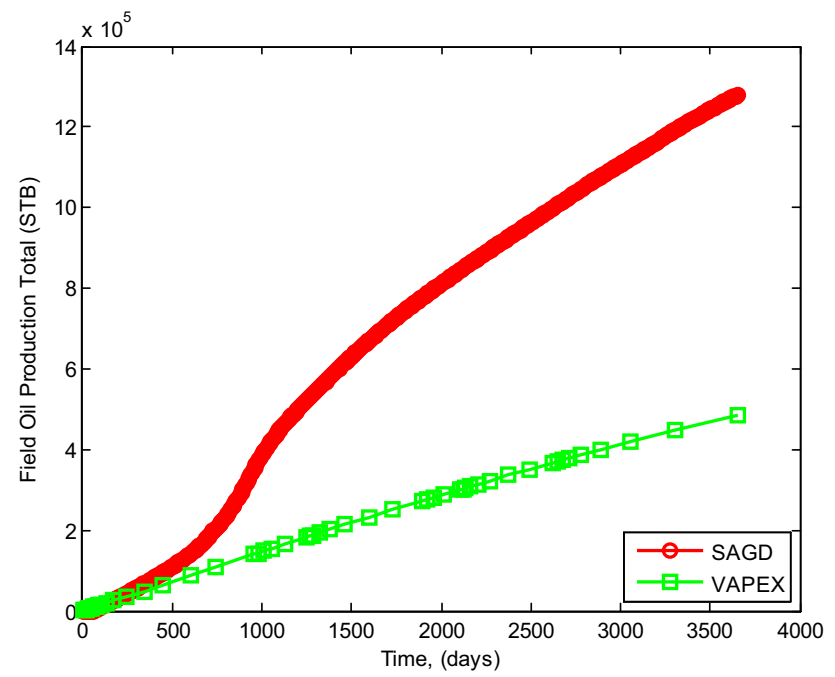

Fig. 21 Cumulative oil production, SAGD and VAPEX

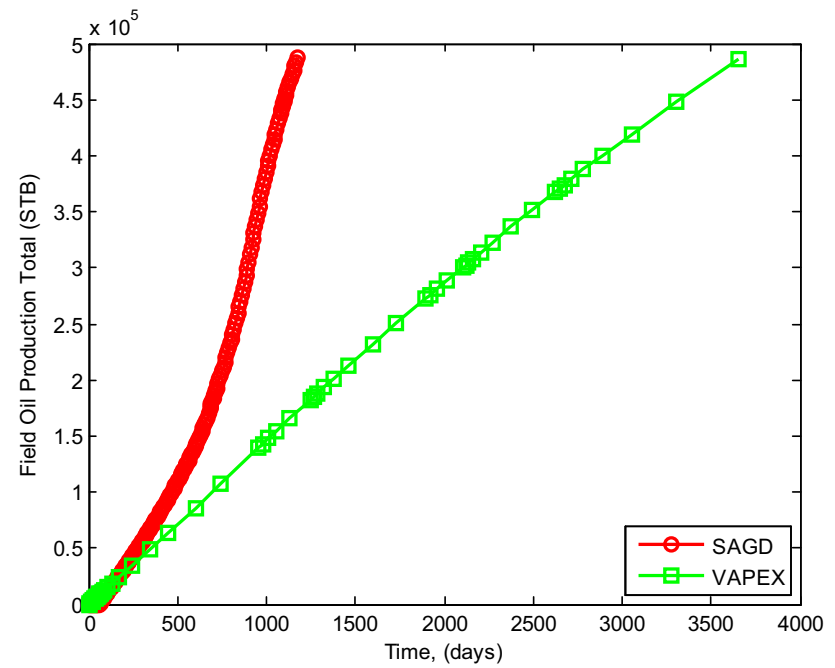

Fig. 22 Time for equivalent production in both processes

numerical simulation of SAGD and VAPEX processes, and its $\log$ permeability distribution is shown in Fig. 8 . The reservoir model is divided into $32 \times 32 \times 10$ grid cells. The dimension of each grid in $\mathrm{x}$ and $\mathrm{y}$ direction is

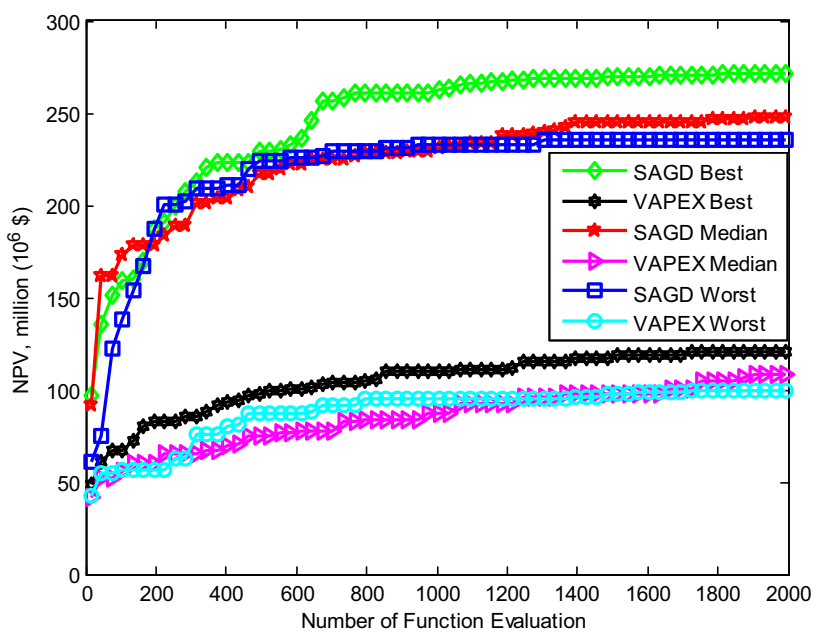

Fig. 23 NPV comparison of SAGD and VAPEX processes, Example

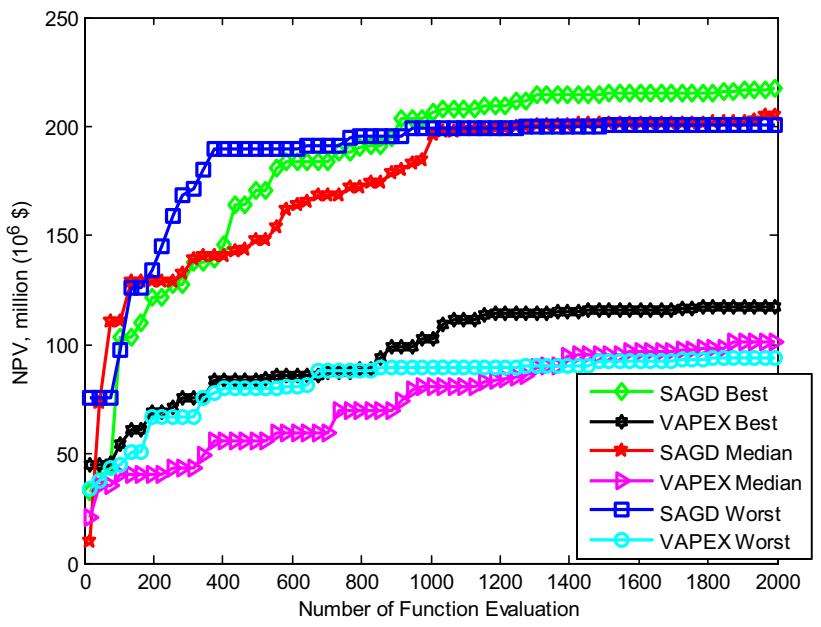

Fig. 24 NPV comparison of SAGD and VAPEX processes, Example 2

$200 \mathrm{ft}$., while in z-direction it is $8.2 \mathrm{ft}$. $(2.5 \mathrm{~m})$. The porosity of both models is different in different layers but within the layer it remains constant; the porosity distribution is shown in Fig. 9. The pertinent fluid and fluid-rock properties are illustrated in Figs. 10, 11 and 12. The reservoir properties of both SAGD and VAPEX models are shown in Table 2 (Awotunde et al. 2014). The producing duration of both SAGD and VAPEX processes was considered as 10 years in the optimization problem. The steam quality of eighty-five percent $(85 \%)$ and injection temperature of four fifty degree Fahrenheit $\left(450{ }^{\circ} \mathrm{F}\right)$ was used. For the simulation of SAGD process to commence effectively, it is necessary to preheat both 
Table 3 Optimized parameters of SAGD and VAPEX processes, Example 1

\begin{tabular}{|c|c|c|c|c|c|c|}
\hline \multirow[t]{2}{*}{ Well } & \multicolumn{3}{|l|}{ SAGD } & \multicolumn{3}{|l|}{ VAPEX } \\
\hline & Rate (STB/D) & Vertical separation (ft.) & Well length (ft.) & Rate (STB/D) & Vertical separation (ft.) & Well length (ft.) \\
\hline P1 & 863 & 8.2 & 2000 & 431 & 41 & 2059 \\
\hline I1 & 0 & & & 835 & & \\
\hline $\mathrm{P} 2$ & 1000 & 8.2 & 2126 & 266 & 8.2 & 2040 \\
\hline I2 & 0 & & & 745 & & \\
\hline P3 & 1000 & 8.2 & 2059 & 915 & 41 & 2059 \\
\hline I3 & 117 & & & 1000 & & \\
\hline P4 & 807 & 8.2 & 2000 & 593 & 8.2 & 2088 \\
\hline I4 & 0 & & & 1000 & & \\
\hline P5 & 905 & 8.2 & 905 & 811 & 41 & 2000 \\
\hline I5 & 0 & & & 1000 & & \\
\hline
\end{tabular}

Table 4 Optimized parameters of SAGD and VAPEX processes, Example 2

\begin{tabular}{|c|c|c|c|c|c|c|}
\hline \multirow[t]{2}{*}{ Well } & \multicolumn{3}{|l|}{ SAGD } & \multicolumn{3}{|l|}{ VAPEX } \\
\hline & Rate (STB/D) & Vertical separation (ft.) & Well length (ft.) & Rate (STB/D) & Vertical separation (ft.) & Well length (ft.) \\
\hline P1 & 717 & 10.25 & 2080 & 234 & 30.75 & 2080 \\
\hline I1 & 957 & & & 990 & & \\
\hline $\mathrm{P} 2$ & 947 & 10.25 & 2080 & 304 & 20.5 & 1946 \\
\hline $\mathrm{I} 2$ & 740 & & & 1000 & & \\
\hline P3 & 969 & 10.25 & 2005 & 1000 & 10.25 & 2049 \\
\hline I3 & 168 & & & 1000 & & \\
\hline P4 & 39 & 41 & 2086 & 875 & 10.25 & 2080 \\
\hline I4 & 161 & & & 913 & & \\
\hline P5 & 208 & 10.25 & 1979 & 972 & 30.75 & 2086 \\
\hline I5 & 95 & & & 893 & & \\
\hline
\end{tabular}

injector and producer with the help of either steam injection or heater. The preheating of the grid blocks connected to wells creates communication of fluids in the vicinity of the wells and helps in the mobilization of oil toward the producer. It was reported that the heating period should be uniform otherwise it would cause failure to the SAGD process (Akinboyewa et al. 2010). To simulate the heating period, heaters were used in the simulator (Eclipse 300, Thermal). The heating rate of 4E6 Btu/day and a preheating period of 60 days were used in SAGD simulations.

\section{Example 2: reservoir with distributed permeability field}

In this example, a synthetic channel reservoir is used for numerical simulation of SAGD and VAPEX processes. The reservoir is discretized into $40 \times 40 \times 8$ grid blocks, each block of size $160 \mathrm{ft} \times 160 \mathrm{ft} \times 10.25 \mathrm{ft}$. The permeability distribution of layer 1-2, layer 3-4, layer 5-6 and layer 7-8 is same, and the different distribution between layers is shown in Fig. 13. Other reservoir and fluid properties were same as described in Example 1. The NPV was computed 


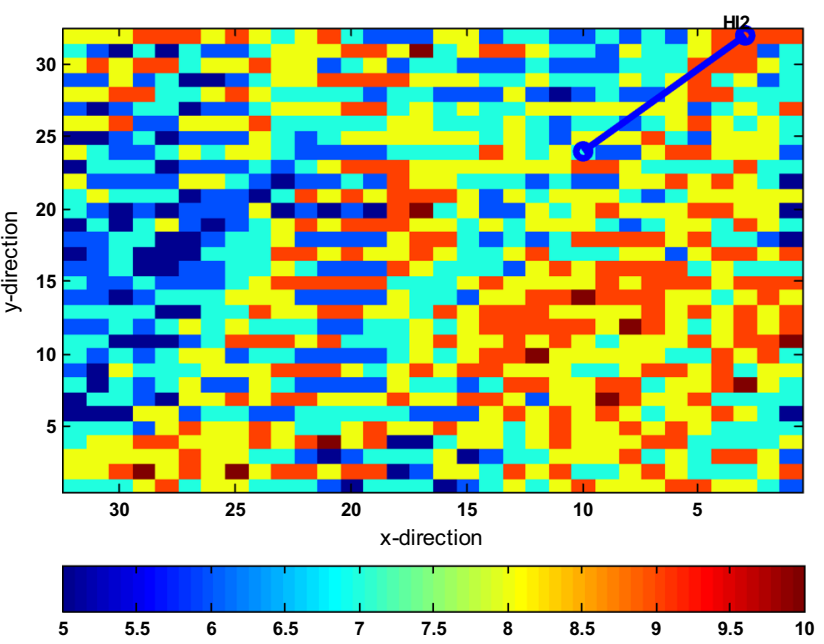

(a)

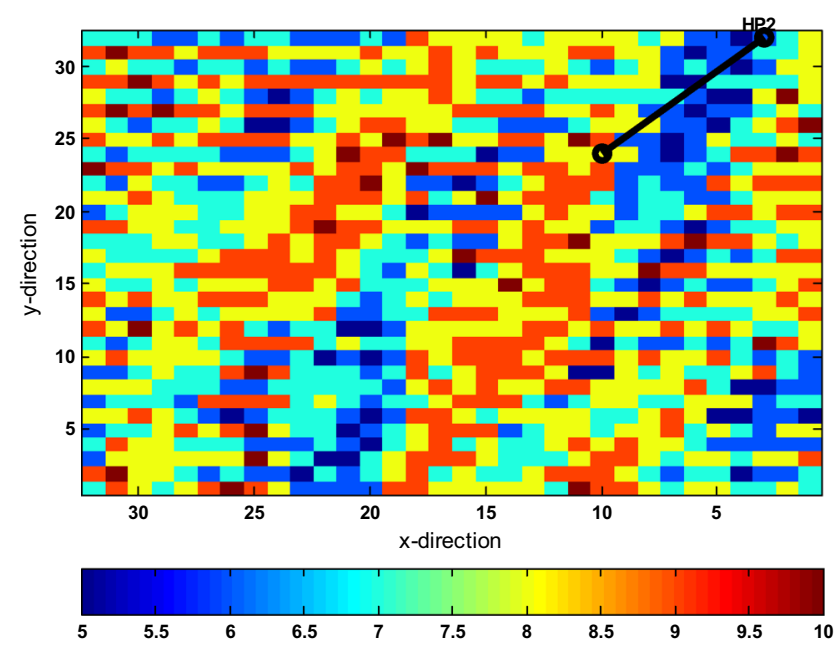

(b)

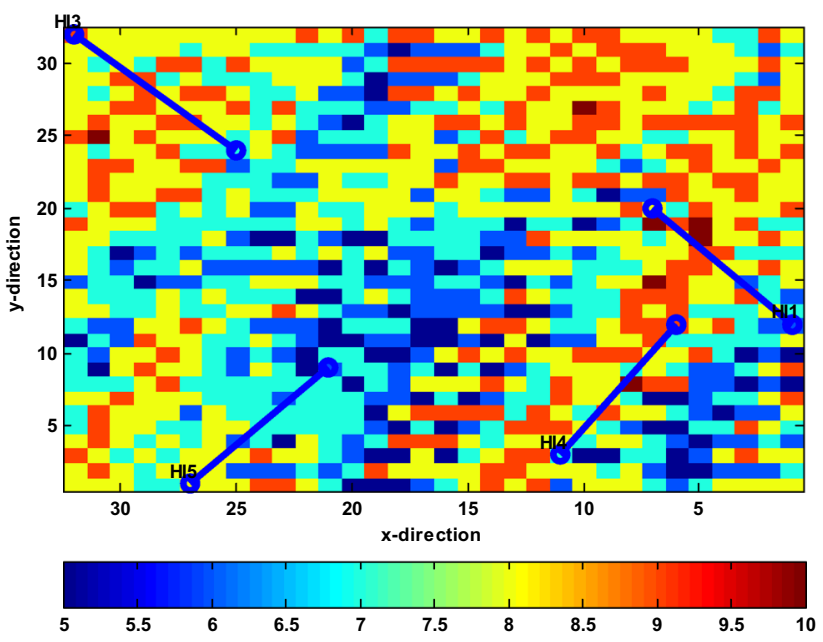

(c)

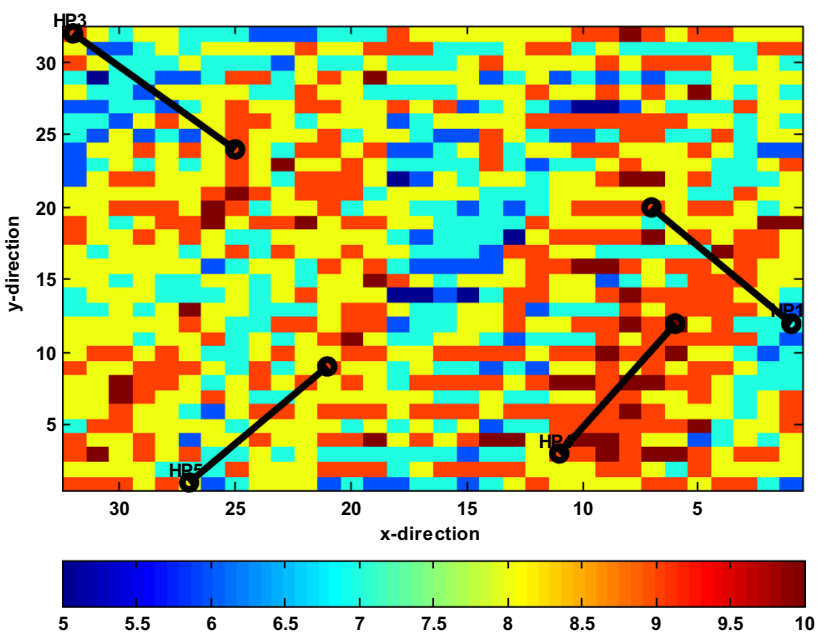

(d)

Fig. 25 Example 1, best solution of well locations for SAGD model in 2D ( $x-y$ plane), a layer 4, b layer 5, c layer 9, d layer 10, injectors are represented by blue lines, whereas producers are in black

for a 10 -year operating period, and approximately 2000 function evaluations were used in the search for the highest NPV. We estimate the well controls, well locations and the vertical separation between injector and producer simultaneously.

\section{Sensitivity analysis}

In this study, we conducted the sensitivity study of SAGD and VAPEX processes for the parameters that are; well length, vertical separation and well spacing on Example 2. For well length and vertical separation, we used single well to calculate the NPV. However, for the well spacing four well are used to test the spacing effect as per the procedure described in the well constraint section. The effect of vertical separation on NPV was analyzed at different well lengths as shown in Fig. 14 and Fig. 15 for SAGD and VAPEX processes, respectively. At higher vertical separation, NPV starts decreasing for each well length in SAGD while the opposite is observed in VAPEX process. 


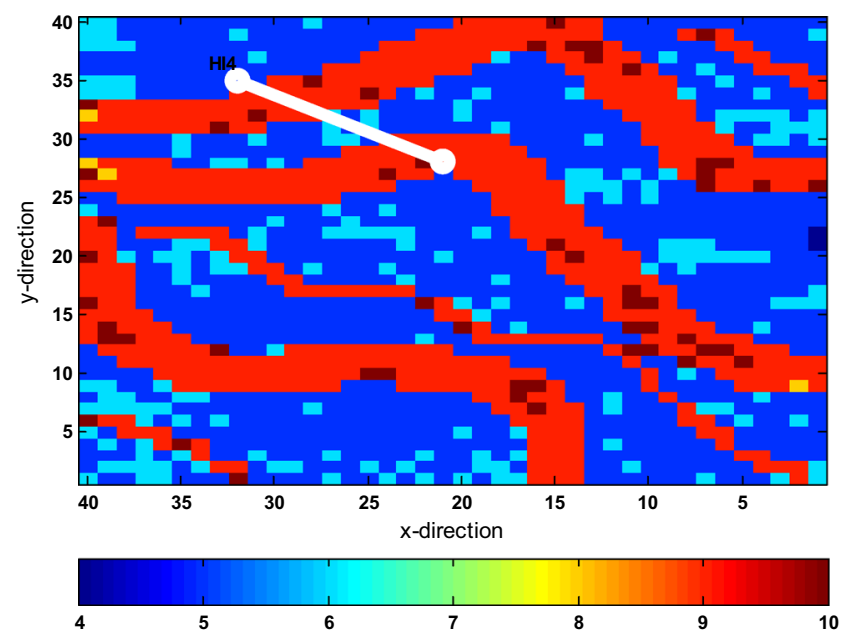

(a)

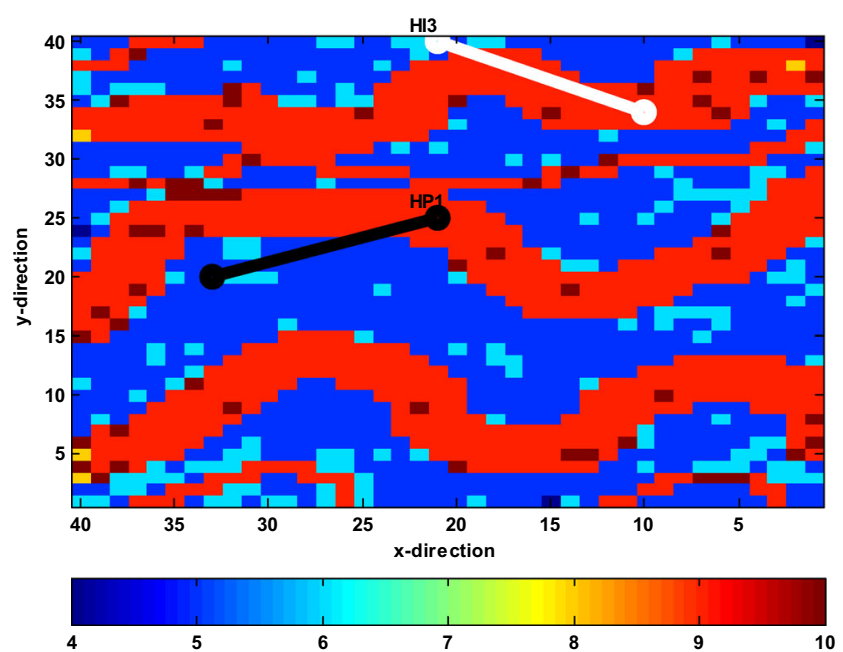

(e)

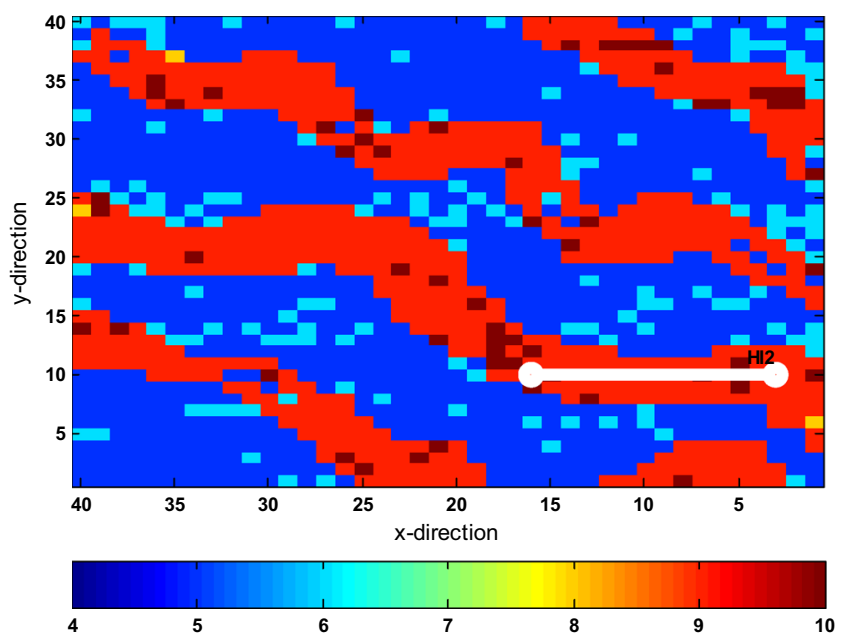

(b)

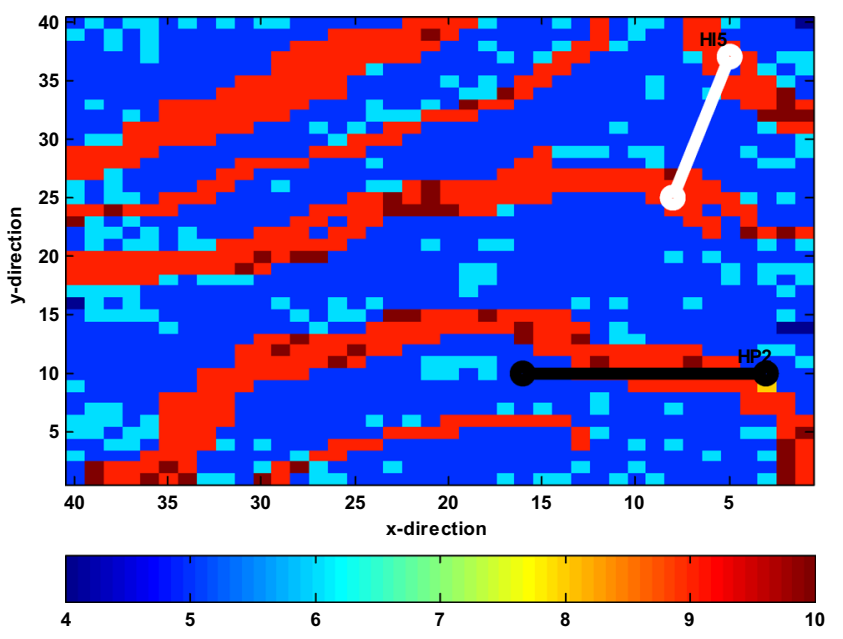

(c)

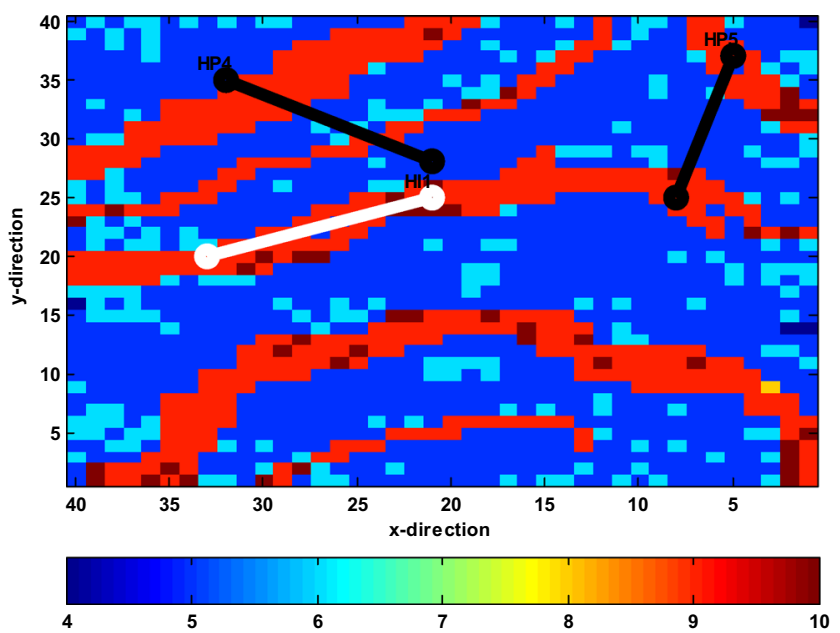

(d)

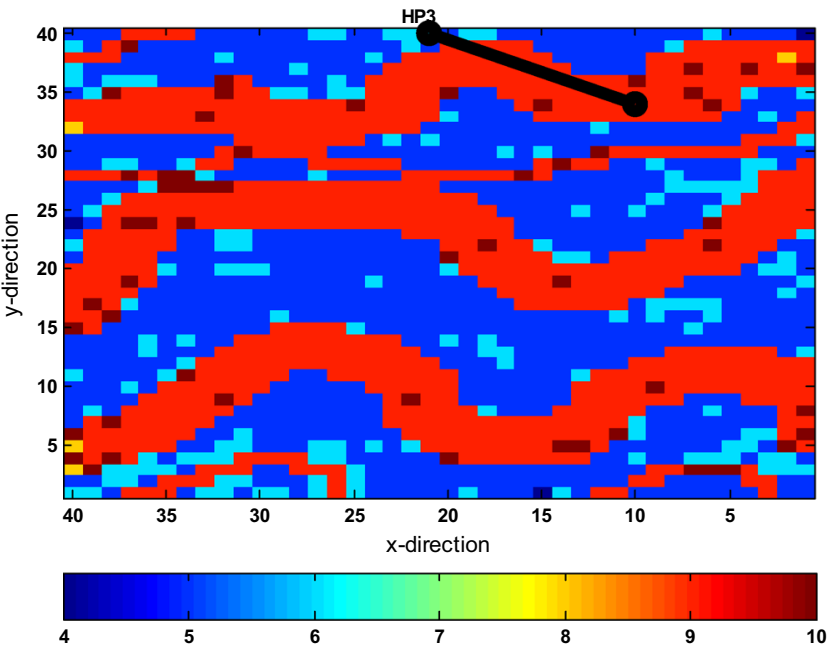

(f)

Fig. 26 Example 2, best solution of well locations for SAGD model in 2D ( $x-y$ plane), a layer 2, b layer 4, c layer 5, d layer 6, e layer 7, f layer 8 , injectors are represented by white lines whereas producers are in black 


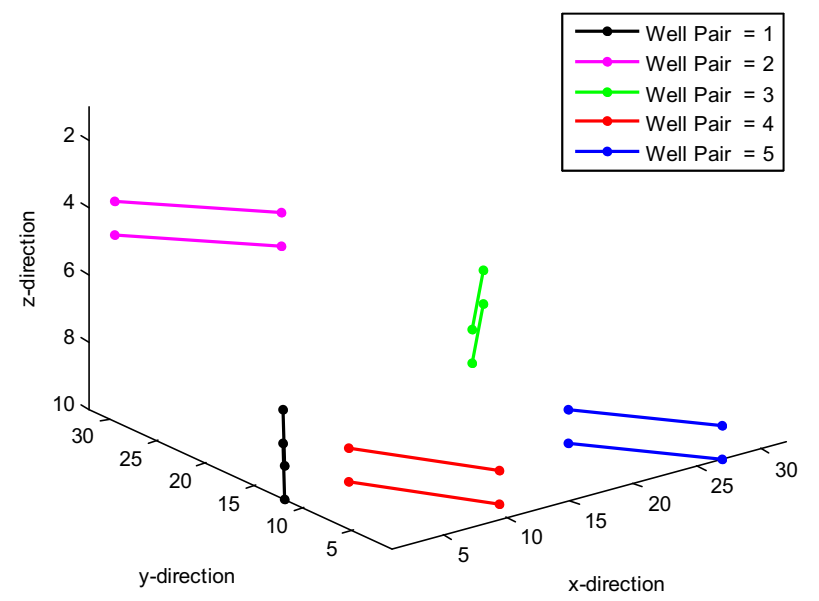

(a)

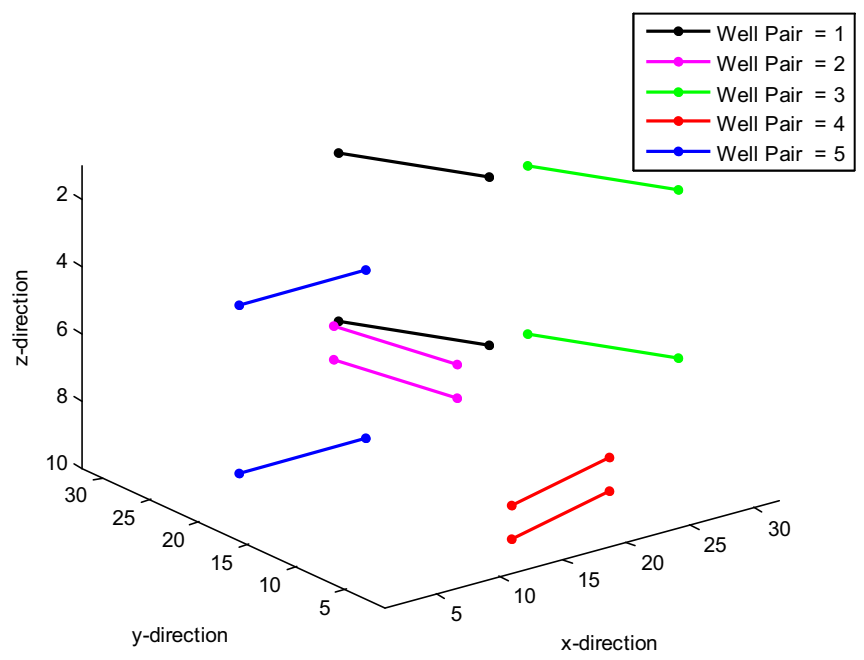

(b)

Fig. 27 Best solution of well locations (3D representation) for Example 1, a SAGD, b VAPEX

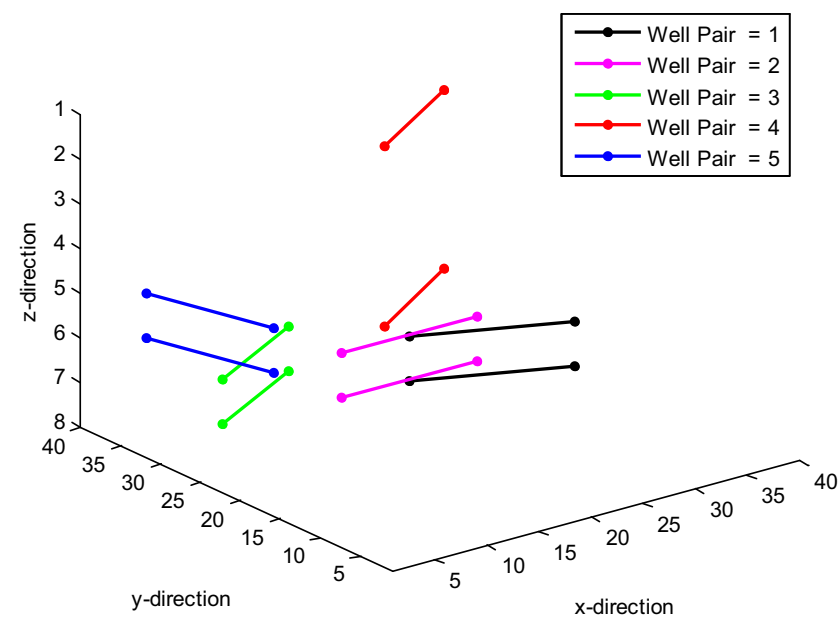

(a)

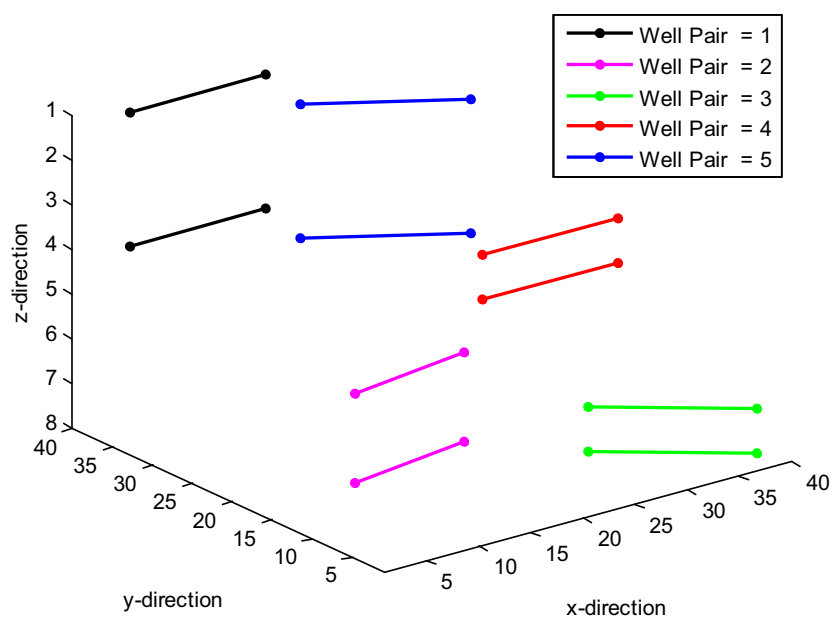

(b)

Fig. 28 Best solution of well locations (3D representation) in Example 2, a SAGD, b VAPEX

Therefore, vertical separation between injector and producer was chosen as a vital parameter in the performance of SAGD and VAPEX processes. The effect of well length on NPV is shown in Fig. 16 and Fig. 17 for SAGD and VAPEX processes, respectively. As expected, oil reservoirs with larger well length yield higher NPV as compared to lower well lengths. However, the probability of constraint violation increases with the increase in well length. Due to the limitation of reservoir area and the largest probability of constraint violation, the maximum well length was limited to 2500 ft. Fig. 18 and Fig. 19 presented the effect of well spacing on NPV for SAGD and VAPEX processes, respectively. The spacing schematic is presented in Fig. 20, and the tolerance (t) between the two well is varied to observe the change in well spacing. Lower well spacing yields higher NPV in SAGD process, while the results show negative effect on VAPEX process. As spacing between the wells increases, increase in NPV becomes negligible in SAGD. Conversely, the optimum value should be obtained for the VAPEX process. The higher NPV value in SAGD process at lower spacing could be due to the higher temperature near the surrounding grids around the well which can form large steam envelope; however, there could be interference between the wells in VAPEX process which results in the lower NPV. In this study, the well spacing tolerance $(\mathrm{t})$ was chosen to be $200 \mathrm{ft}$.

In this study, we also tested the performance of SAGD and VAPEX by keeping all the parameters same such as well placement, well control, well spacing and vertical separation. The graph of total oil production between 


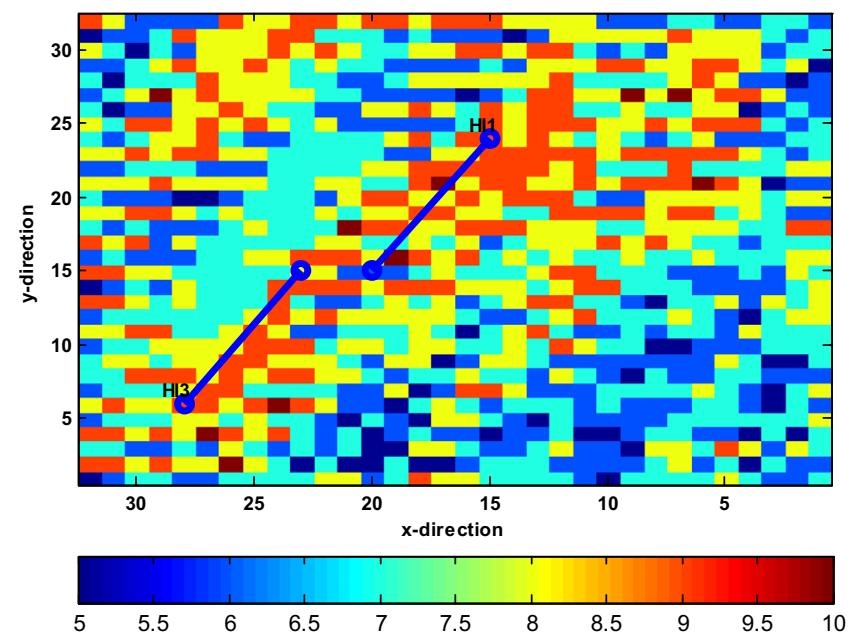

(a)

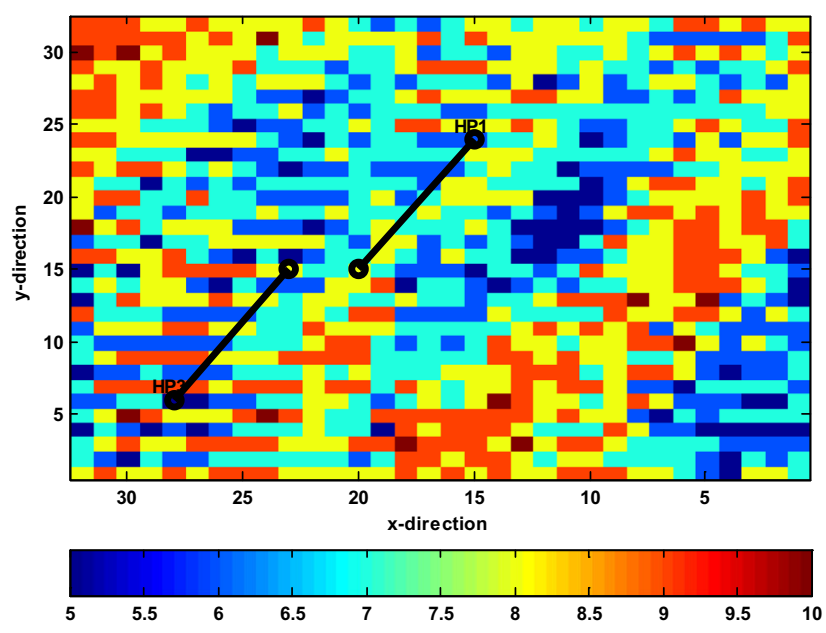

(e)

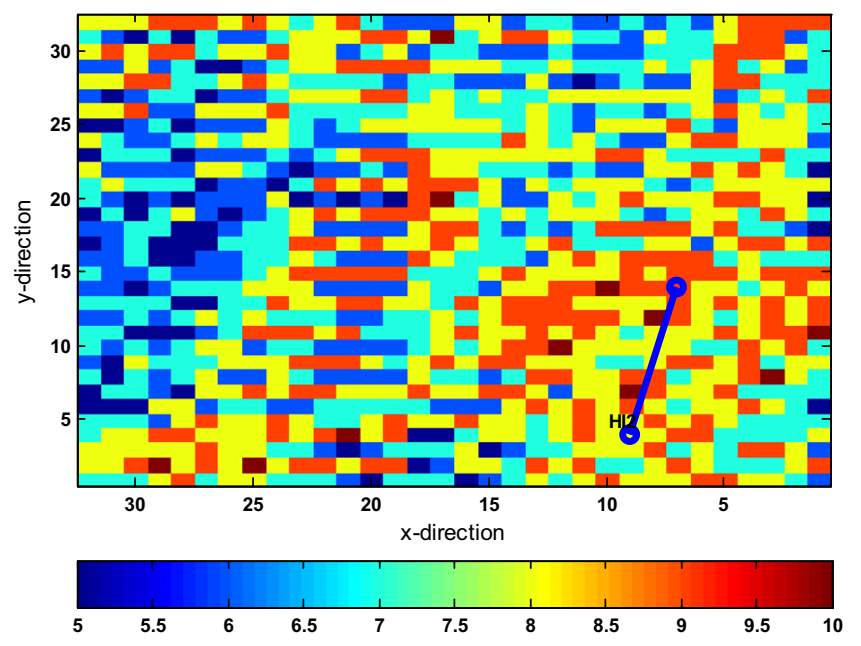

(c)

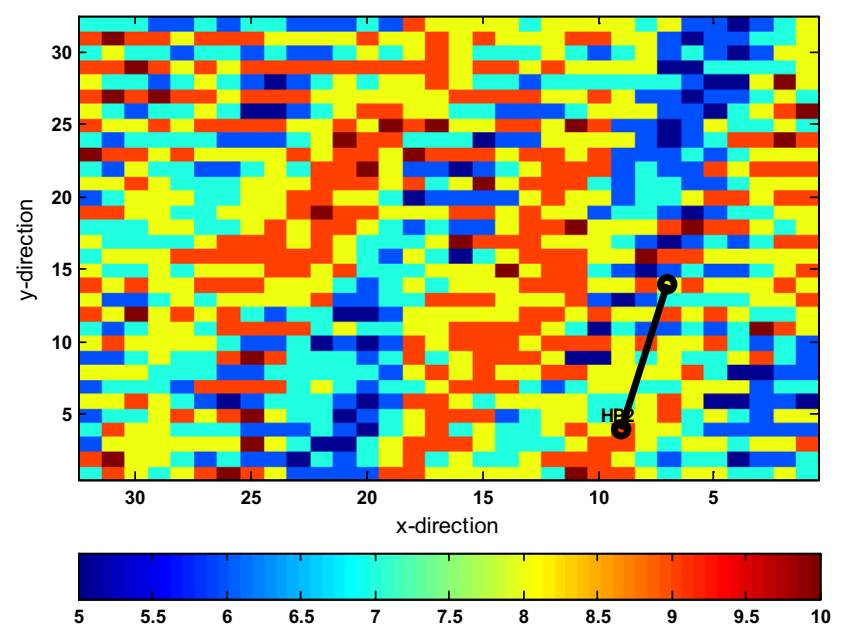

(d)

Fig. 29 Example 1, best solution of well locations for VAPEX model in 2D ( $x-y$ plane), a layer 1, b layer 3, c layer 4, d layer 5, e layer 6, f layer 8 , $\mathbf{g}$ layer 9 , injectors are represented by blue lines whereas producers are in black

SAGD and VAPEX processes for 10 years is shown in Fig. 21. Based on oil production, SAGD has higher cumulative production than VAPEX but when we calculated the NPV of both processes we found that VAPEX $(-9.6 \mathrm{MM} \$)$ is cheap as compared to SAGD (-26.5 MM\$). High operating cost associated with SAGD and amount of water production is the crucial factor. From Fig. 22, it was observed that the SAGD process takes about 3.2 years to produce the same amount of oil the VAPEX process does in 10 years. So it is more accurate to find the NPV values at the same production. Thus, the NPV calculated for the SAGD process is $-7.7 \mathrm{MM} \$$ which is cheaper than VAPEX. Based on this, it is important to optimize the critical parameters in both processes for better performance.

\section{Optimization of vertical separation, injection and production rates with horizontal well pair location}

In both examples, a total of five well parameters were simultaneously optimized; these parameters are the vertical separation between an injector and producer, injection and production rates, and well locations of the injector and producer. Six variables were used for each well pair, i.e., two parameter for heel coordinates, one for the layer, and one for well length, one for vertical separation, and two parameters for injection and production rates of each well. Since both the injector and producer are placed parallel to each other, only the location of horizontal injector is optimized and the vertical separation is added to the layer 


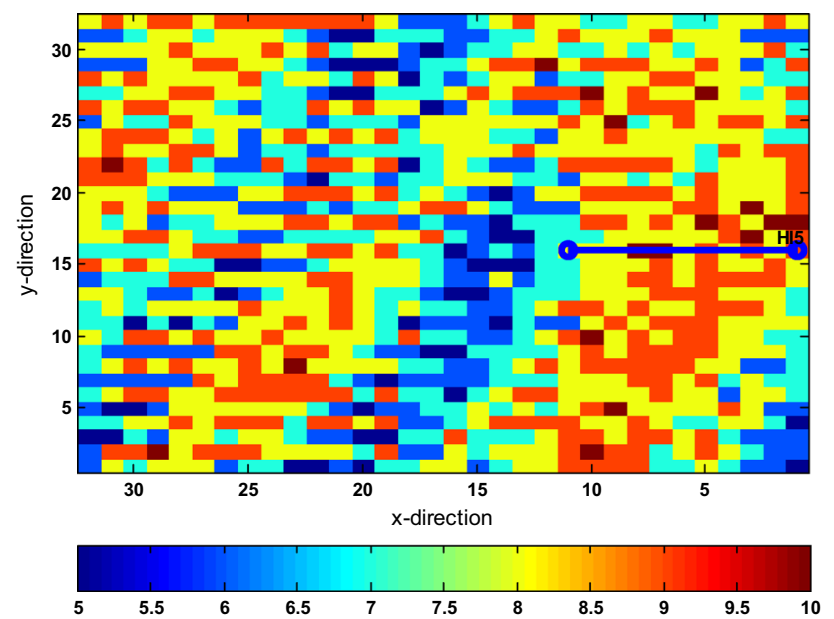

(b)

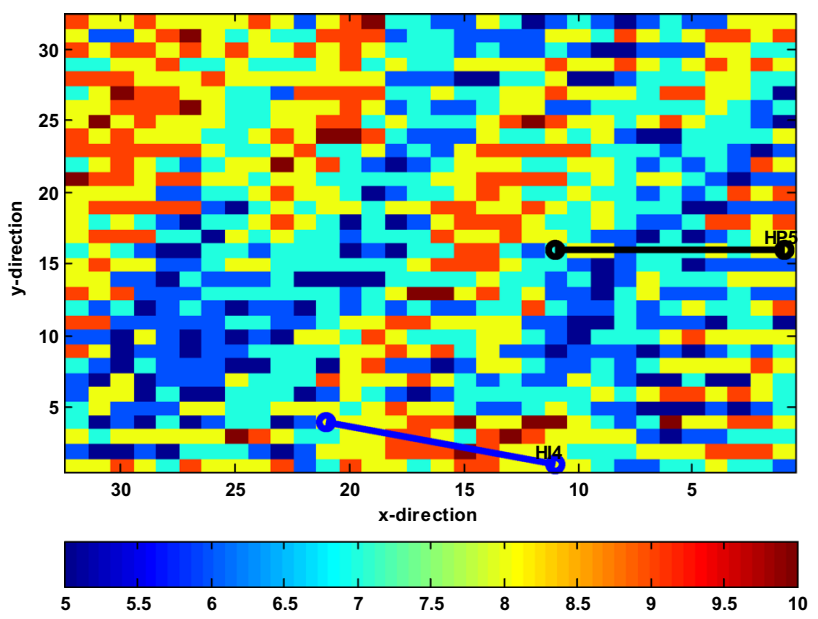

(f)

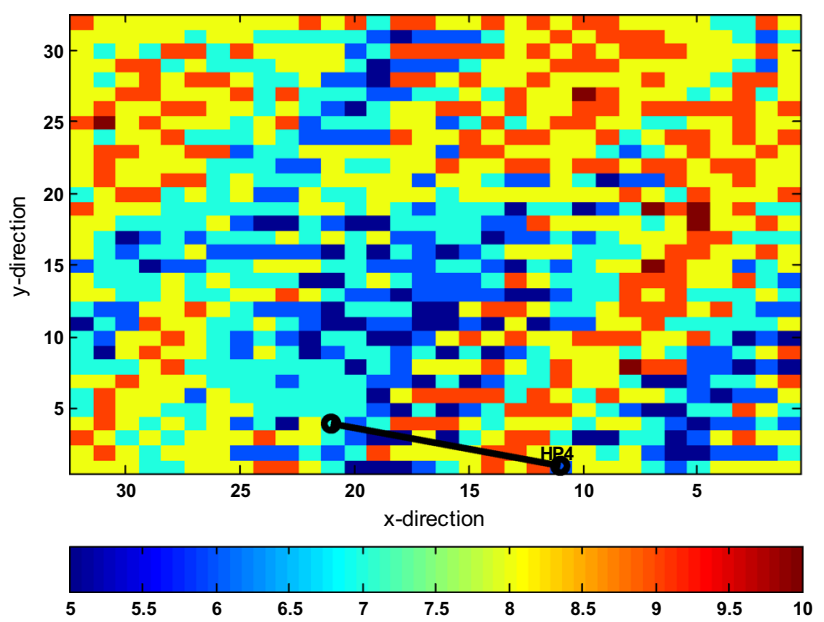

(g)

Fig. 29 continued

value of injector well to get the layer location of the producer while the other parameters which are chosen by the optimizer for the injector remain the same for the producer. A total of six parameters for each well pairs and one rate parameter of each well were optimized that were represented by forty design variables.

The production wells were controlled under a total liquid rate constraint specified by the optimizer. However, a secondary control of minimum bottomhole pressure (BHP of $200 \mathrm{psi}$ ) was enforced to ensure the reservoir production above bubble point pressure. In SAGD process, each injection well was controlled by the water rate obtained from the optimizer. This water is injected in the form of steam while maintaining a maximum BHP limit of 1150 psi. In the VAPEX process, propane is injected as a solvent instead of injecting steam at the same rate defined for the SAGD process. In case, any well pressure goes above the maximum BHP limit, the operating constraint switches from fixed injection rate to fixed pressure constraint to ensure that the injection pressure remains below the formation fracture pressure limit.

\section{Results and discussion}

The yardstick of performances was chosen solely as the NPV attained in the optimization scheme. Those runs were arbitrated to perform better which have higher NPV than that with a lower NPV if the constraints of well spacing were satisfied. To account for statistical variations and nonuniqueness of the process, both SAGD and VAPEX processes were run five times using five different sets of random numbers in the PSO algorithm. In the performance analysis, only the best, median and worst realizations were used for comparison. The comparison between SAGD and VAPEX processes was based on the net present value 


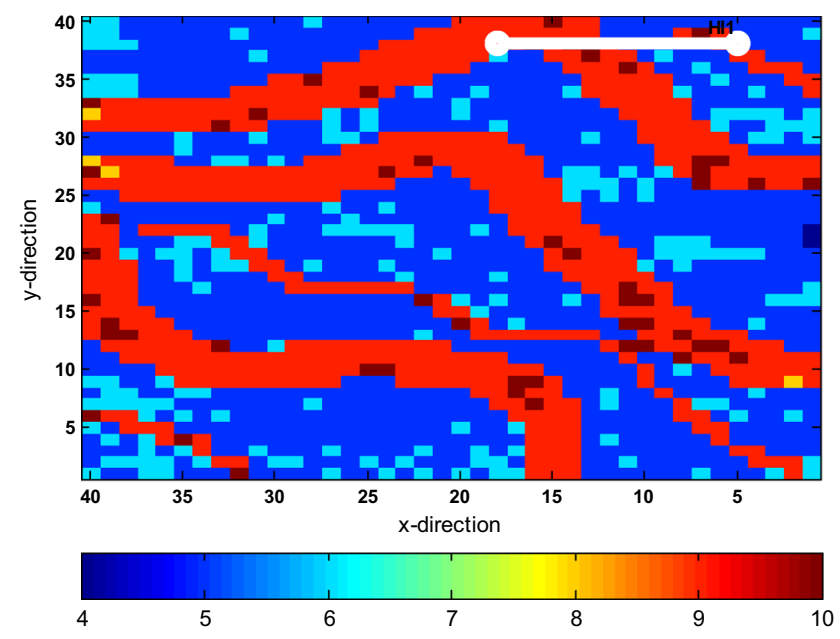

(a)

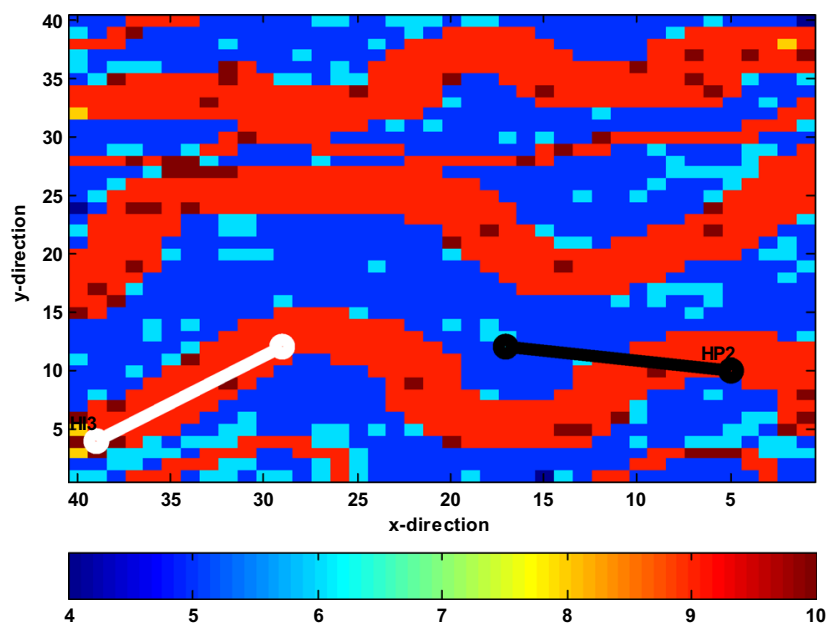

(e)

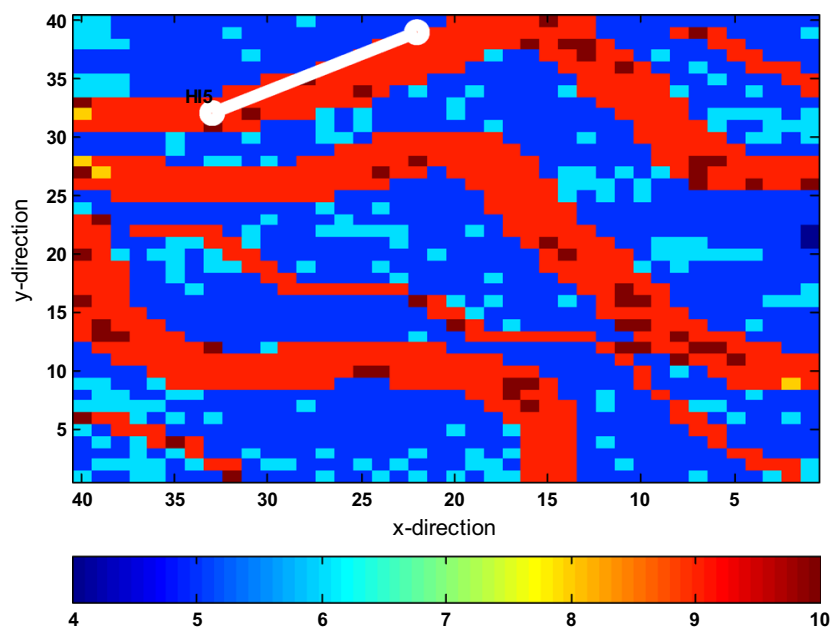

(b)

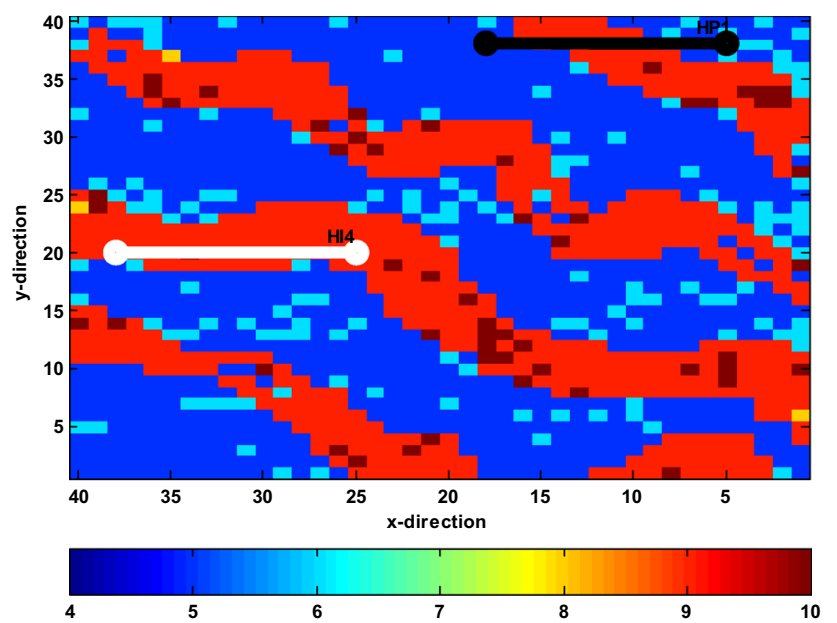

(c)

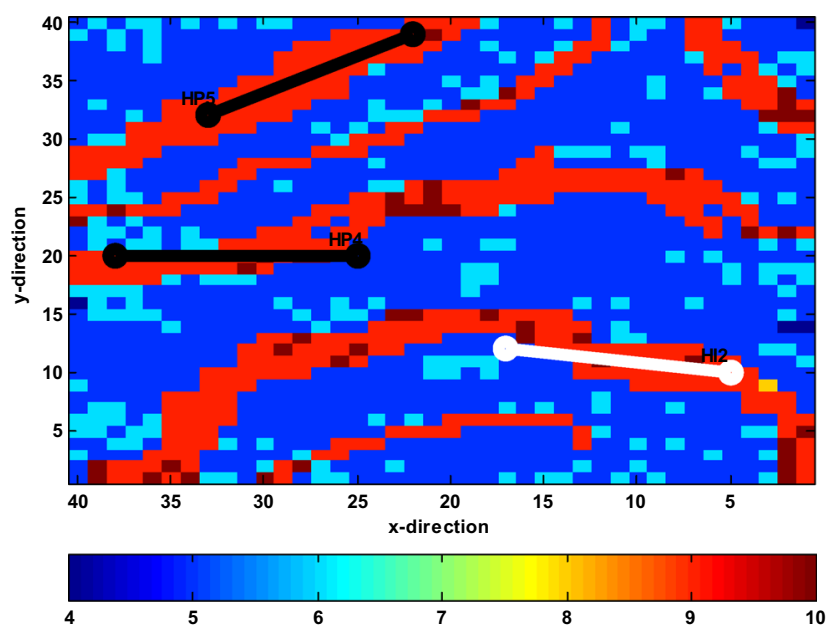

(d)

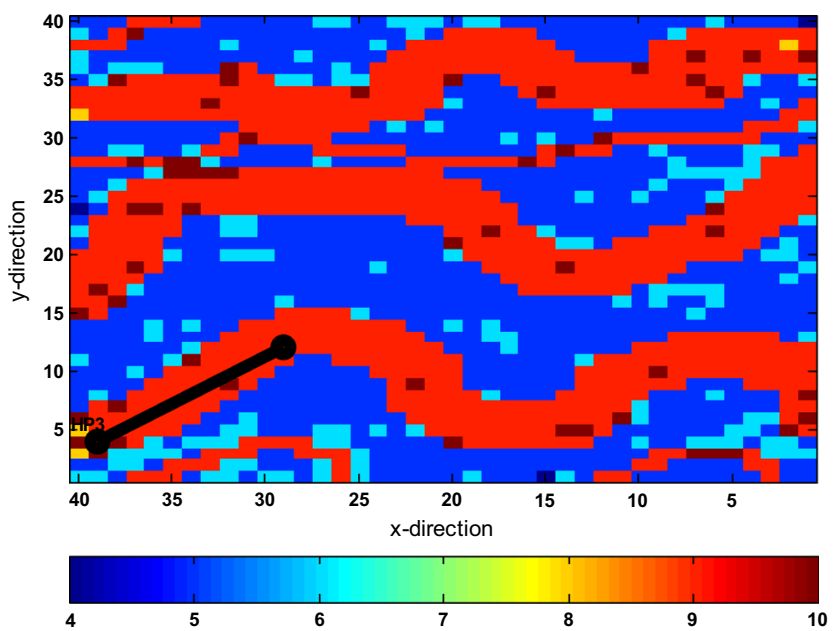

(f)

Fig. 30 Example 2, best solution of well locations for VAPEX model in 2D ( $x-y$ plane), a layer 1, b layer 2, c layer 4, $\mathbf{d}$ layer 5, e layer 7, $\mathbf{f}$ layer 8 , injectors are represented by white lines whereas producers are in black 
obtained from the results of simulation performed during the optimization process. The simulation model of both models was identical, and the important fluid and rock properties were kept same to make an unbiased comparison.

The best, median and worst realizations of NPVs obtained in both examples for SAGD and VAPEX are shown in Fig. 23 and Fig. 24. In each solution, SAGD showed better performance in terms of NPV over VAPEX process. The results show better performance of SAGD over the VAPEX process when the parameters were optimized which further supports the claims that have already been presented in the sensitivity analysis. The SAGD process produces more oil, is cheaper and produces much faster when compared to the VAPEX process. The heterogeneity present in both models could be one of the reasons for low VAPEX performance as it was discussed by Jiang (1996). However, the performance of both operations is highly dependent on controls. The optimized parameters of both processes are listed in Tables 3 and 4 for example 1 and 2, respectively.

For the SAGD process, optimized well locations obtained from the best realization are presented in Fig. 25 and Fig. 26 for example 1 and 2, respectively. In both examples of SAGD process, the optimizer placed the injectors and producers very close to each other for most of the well pairs having the vertical separation of $8.2 \mathrm{ft}$. that is represented in Fig. 27a and Fig. 28a. However, in the VAPEX process the optimizer placed the injector and producer apart form each other as compared to SAGD for most of the well pairs. In both examples of the VAPEX process, we observed large vertical spacing between the well pairs as shown in Fig. 27b and Fig. 28b. The optimized well locations obtained in VAPEX process from the best realization are presented in Fig. 29 and Fig. 30 for example 1 and 2, respectively.

\section{Conclusions}

Based on the results, it is evident that the stochastic optimization performed well in both SAGD and VAPEX processes.

- In this study, we have presented a method to enforce minimum well spacing constraint for horizontal well placement optimization. A well spacing constraint method based on the penalty approach was used to constrain the wells in the reservoir. Constraining circles and ellipses were placed around vertical section and horizontal wells, respectively, to indicate the areas within which no other wells should be placed. The methodology proves to perform well for both processes.
- Particle swarm optimization (PSO) is successfully implemented to optimize the parameters in Well Placement Optimization (WPO) and Well Control Optimization (WCO).

- The comparison of SAGD and VAPEX processes was conducted based on two examples and sensitivity analysis.

- The obtained NPV and the outcomes indicate better performance of SAGD than the VAPEX process.

Acknowledgements The authors would like to acknowledge the support provided by King Abdulaziz City for Science and Technology (KACST) through the Science \& Technology Unit at King Fahd University of Petroleum and Minerals (KFUPM) for funding this work through project No. 12-OIL2998-04 as part of the National Science, Technology and Innovation Plan.

Open Access This article is distributed under the terms of the Creative Commons Attribution 4.0 International License (http:// creativecommons.org/licenses/by/4.0/), which permits unrestricted use, distribution, and reproduction in any medium, provided you give appropriate credit to the original author(s) and the source, provide a link to the Creative Commons license, and indicate if changes were made.

\section{References}

AED (Alberta Economic Development). Oil Sands Industry Update. Available at Alberta Dept. of Energy Website: http://www. energy.gov.ab.ca/com/default.htm. March 2004

Akhondzadeh H, Fattahi A (2015) Impact of well configuration on performance of steam-based gravity drainage processes in naturally fractured reservoirs. J Petrol Explor Prod Technol $5(1): 13-25$

Akinboyewa J, Das SK, Wu YS, Kazemi H (2010) Simulation of expanding solvent-steam assisted gravity drainage in a field case study of a Bitumen oil reservoir. In: SPE Improved Oil Recovery Symposium. Society of Petroleum Engineers

Artus V, Durlofsky LJ, Onwunalu J, Aziz K (2006) Optimization of nonconventional wells under uncertainty using statistical proxies. Comput Geosci 10(4):389-404. doi:10.1007/s10596-0069031-9

Awotunde AA (2016) Generalized field-development optimization with well-control zonation. Comput Geosci 20(1):213-230

Awotunde AA, Naranjo C (2014) Well placement optimization constrained to minimum well spacing. In: SPE Latin America and Caribbean Petroleum Engineering Conference. Society of Petroleum Engineers

Awotunde AA, Sibaweihi N (2014) Consideration of voidagereplacement ratio in well-placement optimization. SPE Econ Manag 6(01):40-54

Awotunde AA, Sahib Azad M, Naranjo Suarez C (2014) Improving Steam Drive in Naturally Fractured Reservoirs: A Global Optimization Strategy. In: SPE Latin America and Caribbean Petroleum Engineering Conference. Society of Petroleum Engineers

Badru O, Kabir CS (2003) Well placement optimization in field development. In: SPE Annual Technical Conference and Exhibition. Society of Petroleum Engineers 
Birrell GE, Putnam PE (2000) A Study of the influence of reservoir architecture on SAGD steam chamber development at the Underground Test Facility, Northeastern Alberta, Canada, using a graphical analysis of temperature profiles. In: Canadian International Petroleum Conference. Petroleum Society of Canada

Bouzarkouna Z, Ding DY, Auger A (2012) Well placement optimization with the covariance matrix adaptation evolution strategy and meta-models. Comput Geosci 16(1):75-92

Bukhamsin AY, Farshi MM, Aziz K (2010) Optimization of multilateral well design and location in a real field using a continuous genetic algorithm. Soc Pet Eng. doi:10.2118/136944MS

Butler R (1998) SAGD comes of age! J Can Pet Technol 37(7):9-12

Butler AM, Jiang Q (1997) Improved VAPEX performance using widely spaced horizontal injectors and producers. In: Technical Meeting/Petroleum Conference Of The South Saskatchewan Section. Petroleum Society of Canada

Butler RM, Jiang Q (2000) Improved recovery of heavy oil by VAPEX with widely spaced horizontal injectors and producers. J Can Pet Technol 39(1):48-56

Butler RM, Mokrys IJ (1991) A new process (VAPEX) for recovering heavy oils using hot water and hydrocarbon vapour. J Can Pet Technol 30(1):97-106

Butler RM, Mokrys IJ (1998) Closed-loop extraction method for the recovery of heavy oils and bitumens underlain by aquifers: the VAPEX process. J Can Pet Technol 37(04):41-50

Byrne C (2008) Sequential unconstrained minimization algorithms for constrained optimization. Inverse Probl 24(1):015013

Card CC, Chakrabarty N, Gates ID (2006) Automated Global Optimization of Commercial SAGD Operations. In: Canadian International Petroleum Conference. Petroleum Society of Canada

Clerc M (1999) The swarm and the queen: towards a deterministic and adaptive particle swarm optimization. In Evolutionary Computation, 1999. CEC 99. Proceedings of the 1999 Congress on (Vol. 3). IEEE

Coello CAC, Carlos A (1999). A survey of constraint handling techniques used with evolutionary algorithms. Lania-RI-99-04, Laboratorio Nacional de Informática Avanzada

Das SK, Butler RM (1995) Extraction of heavy oil and bitumen using solvents at reservoir pressure. In: Technical meeting/petroleum conference of the South Saskatchewan section. Petroleum Society of Canada

Eberhart RC, Kennedy J (1995) A new optimizer using particle swarm theory. In: Proceedings of the sixth international symposium on micro machine and human science (Vol. 1, pp. 39-43)

Edmunds N, Chhina H (2001) Economic optimum operating pressure for SAGD projects in Alberta. J Can Pet Technol 40(12):13-17

Edmunds NR, Kovalsky JA, Gittins SD, Pennacchioli ED (1994) Review of phase A steam-assisted gravity-drainage test. SPE Reserv Eng 9(02):119-124

Egermann P, Renard G, Delamaide E (2001) SAGD performance optimization through numerical simulations: Methodology and field case example. In: SPE International Thermal Operations and Heavy Oil Symposium. Society of Petroleum Engineers

Emerick AA, Silva E, Messer B, Almeida LF, Szwarcman D, Pacheco MAC, Vellasco MMBR (2009) Well placement optimization using a genetic algorithm with nonlinear constraints. In: SPE reservoir simulation symposium. Society of Petroleum Engineers

Engelbrecht AP (2005) Fundamentals of Computational Swarm Intelligence. Willy, West Sussex

Farshi MM (2008) Improving genetic algorithms for optimum well placement (Doctoral dissertation, Stanford University)
Fernandez-Martinez JL, Garcia-Gonzalo E (2011) Stochastic stability analysis of the linear continuous and discrete PSO models. IEEE Trans Evolut Comput 15(3):405-423

Forouzanfar F, Li G, Reynolds AC (2010) A two-stage well placement optimization method based on adjoint gradient. In: SPE Annual Technical Conference and Exhibition. Society of Petroleum Engineers

Forouzanfar F, Poquioma WE, Reynolds AC (2015) A covariance matrix adaptation algorithm for simultaneous estimation of optimal placement and control of production and water injection wells. Soc Pet Eng. doi:10.2118/173256-MS

Gates ID, Chakrabarty N (2006) Optimization of steam assisted gravity drainage in McMurray reservoir. J Can Pet Technol 45(9):54-62

Guyaguler B, Horne RN, Rogers L, Rosenzweig JJ (2000) Optimization of well placement in a Gulf of Mexico waterflooding project. In: SPE annual technical conference and exhibition. Society of Petroleum Engineers. doi:10.2118/63221-MS

Isebor OJ, Echeverría Ciaurri D, Durlofsky LJ (2014) Generalized field-development optimization with derivative-free procedures. Soc Pet Eng. doi:10.2118/163631-PA

Ito Y, Suzuki S (1999) Numerical simulation of the SAGD process in the Hangingstone oil sands reservoir. J Can Pet Technol 38(9):27-35

Jesmani M, Bellout MC, Hanea R, Foss B (2015) Particle Swarm Optimization Algorithm for Optimum Well Placement Subject to Realistic Field Development Constraints. In: SPE Reservoir Characterisation and Simulation Conference and Exhibition. Society of Petroleum Engineers

Jiang Q, Butler RM (1996) Experimental studies on effects of reservoir heterogeneity on the Vapex process. J Can Pet Technol 35(10):46-54

Jin W (1999) Heavy oil recovery using the VAPEX process (Doctoral dissertation, University of Waterloo)

Jorshari K, O'Hara B (2013) A new SAGD-well-pair placement: a field case review. J Can Pet Technol 52(01):12-19

Karmaker K, Maini BB (2003) Applicability of vapor extraction process to problematic viscous oil reservoirs. In: SPE Annual Technical Conference and Exhibition. Society of Petroleum Engineers

Kisman KE, Yeung KC (1995) Numerical study of the SAGD process in the Burnt Lake oil sands lease. In: SPE international heavy oil symposium. Society of Petroleum Engineers

Komery DP, Luhning RW, O'rourke JG (1999) Towards commercialization of the UTF project using surface drilled horizontal SAGD wells. J Can Pet Technol 38(09):36-43

Larter S, Adams J, Gates ID, Bennett B, Huang H (2008) The origin, prediction and impact of oil viscosity heterogeneity on the production characteristics of tar sand and heavy oil reservoirs. J Can Pet Technol 47(1):52-61

Li L, Jafarpour B, Mohammad-Khaninezhad MR (2013) A simultaneous perturbation stochastic approximation algorithm for coupled well placement and control optimization under geologic uncertainty. Comput Geosci 17(1):167-188

Mojarab M, Harding TG, Maini BB (2011) Improving the SAGD performance by introducing a new well configuration. J Can Pet Technol 50(04):9-18

Oduntan AR, Chatzis I, Smith J, Lohi A (2001) Heavy oil recovery using the VAPEX process: scale-up issues. In: Proceedings: Canadian International Petroleum Conference (pp. 2001-127)

Onwunalu JE, Durlofsky LJ (2010) Application of a particle swarm optimization algorithm for determining optimum well location and type. Comput Geosci 14(1):183-198

Orvosh D, Davis L (1993) Shall we repair? genetic algorithmscombinatorial optimizationand feasibility constraints. In:

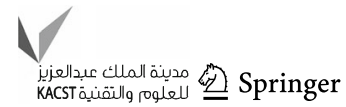


Proceedings of the 5th International Conference on Genetic Algorithms (p. 650). Morgan Kaufmann Publishers Inc

Ozdogan U, Horne RN (2006) Optimization of well placement under time-dependent uncertainty. Soc Pet Eng. doi:10.2118/90091-PA

Parappilly R, Zhao L (2009) SAGD with a Longer Wellbore. Pet Soc Can. doi:10.2118/09-06-71

Queipo NV, Goicochea JV, Pintos S (2002) Surrogate modelingbased optimization of SAGD processes. J Pet Sci Eng 35(1):83-93

Sarma P, Chen WH (2008) Efficient well placement optimization with gradient-based algorithms and adjoint models. In: Intelligent Energy Conference and Exhibition. Society of Petroleum Engineers

Scott GR (2002) Comparison of CSS and SAGD performance in the Clearwater formation at Cold Lake. In: SPE International Thermal Operations and Heavy Oil Symposium and International Horizontal Well Technology Conference. Society of Petroleum Engineers

Singhal AK, Ito Y, Kasraie M (1998) Screening and design criteria for steam assisted gravity drainage (SAGD) projects. In: SPE International Conference on Horizontal Well Technology. Society of Petroleum Engineers

Stalder JL (2007) Cross-SAGD (XSAGD)-An Accelerated Bitumen Recovery Alternative. Society of Petroleum Engineers. doi:10. 2118/97647-PA
Suggett J, Gittins S, Youn S (2000) Christina Lake thermal project. In: SPE/CIM International Conference on Horizontal Well Technology. Society of Petroleum Engineers

Tamer MR, Gates ID (2012) Impact of Different SAGD Well Configurations (Dover SAGD Phase B Case Study). J Can Pet Technol 51(01):32-45

Upreti SR, Lohi A, Kapadia RA, El-Haj R (2007) Vapor extraction of heavy oil and bitumen: a review. Energy Fuels 21(3):1562-1574

Wang C, Li G, Reynolds AC (2007) Optimal well placement for production optimization. In: Eastern Regional Meeting. Society of Petroleum Engineers

Yazdani J, Maini BB (2004) New experimental model design for VAPEX process experiments. In: Canadian International Petroleum Conference. Petroleum Society of Canada

Yee CT, Stroich A (2004) Flue gas injection into a mature SAGD steam chamber at the Dover Project (Formerly UTF). J Can Pet Technol 43(01):54-61

Zandvliet M, Handels M, van Essen G, Brouwer R, Jansen JD (2008) Adjoint-based well-placement optimization under production constraints. SPE J 13(04):392-399 